\title{
Powering Up Developing Countries through Integration?
}

\author{
Emmanuelle Auriol and Sara Biancini
}

\begin{abstract}
Power market integration is analyzed in a two-country model with nationally regulated firms and costly public funds. If the generation costs between the two countries are too similar, negative business stealing outweighs efficiency gains so that, subsequent to integration, welfare decreases in both regions. Integration is welfare enhancing when the cost difference between two regions is large enough. The benefits from export profits increase the total welfare in the exporting country, whereas the importing country benefits from a lower price. In this case, market integration also improves incentives to invest compared to autarky. The investment levels remain inefficient, however, especially for transportation facilities. Free riding reduces incentives to invest in these public-good components of the network, whereas business stealing tends to decrease the capacity to finance new investment. JEL classification: L43, L51, F12, F15, R53
\end{abstract}

The world's electricity demand is projected to double by the year 2030 (International Electricity Agency 2006). Financing the volume of investment required to meet this demand increase is a challenge for developing countries. ${ }^{1}$

Emmanuelle Auriol is a professor at Toulouse School of Economics and a researcher at TSE, ARQADE and IDEI; her email adress is emmanuelle.auriol@tse-fr.eu. Sara Biancini (corresponding author) is a professor at UCBN Caen Basse-Normandie and a researcher at Normandie Universite and CREM; her email address is sara.biancini@unicaen.fr. The authors are grateful for the financial support of the French Development Agency (AFD). Part of this paper was completed while Sara Biancini was a research fellow at the European University Institute. For their help and comments, we thank the seminar audiences at the University of Cergy-Pontoise, the University of Milan, the French Development Agency (AFD), the 2008 EUDN conference, and the JEI 2009 in Vigo. We are also extremely grateful for the comments and suggestions of Claude Crampes, Rafael Moner, Aymeric Blanc, Alexis Bonnel, and Yannick Perez on early versions of this paper. Finally, this paper has greatly benefited from the insightful comments, criticisms, and suggestions of three anonymous referees. We thank them for their input.

1. The total cumulative investment in power generation, transmission, and distribution that is necessary to meet this increase in demand is estimated by the International Electricity Agency 2006 to reach $\$ 11.3$ trillion. This amount covers investments in OECD countries and in rapidly growing developing countries, such as India and China, as well as the investments necessary to relieve the acute power penury experienced by some of the world's poorest nations, especially in Sub-Saharan Africa (International Electricity Agency 2006). Indeed, in 2000, only 40\% of the population of low-income countries had access to electricity, and this percentage dropped to $10 \%$ for the poorest quintile (Estache and Wren-Lewis 2009).

THE WORLD BANK ECONOMIC REVIEW, VOL. 29, NO. 1, pp. 1-40

doi:10.1093/wber/lht021

Advance Access Publication July 21, 2013

(C) The Author 2013. Published by Oxford University Press on behalf of the International Bank

for Reconstruction and Development / THE WORLD BANK. All rights reserved. For permissions, please e-mail: journals.permissions@oup.com 
With scarce public resources, little assistance from the private sector, and limited aid, ${ }^{2}$ these countries attempt to address their investment needs by creating regional power markets. Integrated power pools should allow for the better use of existing resources and infrastructures between the countries involved and for the realization of projects that would otherwise be oversized for an isolated country. In most cases, this integration is likely to occur in the absence of legitimate supranational regulation. This paper studies the costs and benefits of this partial economic integration. This paper shows that coordination problems between independent regulators prevent them from efficiently using the stock of existing infrastructure, and they distort countries' incentives to invest in new generation and, more importantly, in interconnection facilities. These countries' competition for market shares limits the benefit of integration. Because of these losses, the difference in these countries' generation costs must be large for a regional power pool to successfully emerge.

Consistent with the theory, cost complementarities in generation are the main engine of integration in electricity markets. For instance, in South America, several generation and interconnection projects have been launched to exploit efficiency gains between countries that do not have sufficient energy resources, such as Brazil or Chile, and countries that have a large supply potential in terms of hydropower, heavy oil, and gas, such as Paraguay, Venezuela, Bolivia, and Peru. Similarly, the Greater Mekong Subregion countries, such as Thailand and Vietnam, want to integrate with countries with a large supply potential in terms of hydropower and gas resources, such as Laos and Myanmar. To exploit the potential gains from cross-border trade and to increase their system efficiency, African countries, sustained by the World Bank, have created several regional power pools: the South African Power Pool (SAPP), the West African Power Pool (WAPP), the Central African Power Pool (CAPP), and the East African Power Pool (EAPP), along with interconnection initiatives in North Africa with ties to the Middle East. The pools, which were created to overcome the Sub-Sahara's acute shortage problems, are designed to foster the emergence of major projects, such as large hydroelectricgeneration facilities. These projects are unlikely to be achieved otherwise because they are oversized for the local demand. For instance, the hydro potential of the Democratic Republic of Congo alone is estimated to be sufficient to provide three times as much power as is currently consumed in Africa. Large hydroelectric projects, such as the Grand Inga in the region of the Congo River and the projects for the Senegal River basin, could benefit all countries in the region. ${ }^{3}$ The challenging question, however, is how to finance these projects.

2. The share of infrastructure assistance in the energy and communications sectors has dramatically declined in recent years (Estache and Iimi 2008). At the same time, as Estache and Wren-Lewis 2009 note, "For many countries, particularly those with the lowest income, private-sector participation has been disappointing". As rich countries emerge from the global financial crisis with high debt, it is unlikely that development assistance will increase significantly in the near future, and there is a risk that aid to large infrastructure projects could be reduced.

3. For West Africa, Sparrow et al. 2002 estimate the potential cost reduction associated with market integration at between 5 and $20 \%$ (based on the expansion of the thermal and hydroelectric capacities). 
Electricity is a non-storable good that requires large specific investments, such as transportation and interconnection facilities, before it can be transferred to other markets. For instance, it is estimated that some $26 \mathrm{GW}$ of interconnectors, at a cost of $\$ 500$ million per year, are lacking for the creation of a regional power-trading market in SSA (Rosnes and Vennemo 2008). This investment requirement is a major difference between electricity and the trade of standard commodities. In the absence of a binding commitment mechanism, firms and governments are unwilling to sink huge investments with the sole purpose of selling electricity to a neighboring country in the future. Once these specific investments are realized, the investing country would incur a classic hold-up problem. The trade partner could always renegotiate the price, but the investor has no ability to sell the energy elsewhere. This commercial risk is particularly acute in developing countries. ${ }^{4}$ In this context, the creation of a power pool, with a free trade agreement and a sound mechanism for dispute resolution, mitigates commercial, political, and regulatory risks because it strengthens the coordination between countries and limits political interference. This structure has been chosen to promote investment in neighboring developing countries that are endowed with unequal energy resources. ${ }^{5}$

This paper studies the impact of the creation of a regional power pool (i.e., an integrated electricity market with a free trade agreement) on energy production and on incentives to invest in generation and transmission infrastructures in a two-countries model. Because the integration is imperfect (i.e., it is neither political nor fiscal), governments focus on their own national welfare. Governments are biased in favor of their national (public) firms because the governments are the residual claimant for their profits and losses. Theoretically, the relevant analytical framework is asymmetric regulation (i.e., each firm is nationally regulated) with costly public funds. This framework was introduced by Caillaud 1990 and Biglaiser and Ma 1995 to study the liberalization of regulated industries. ${ }^{6}$ Because market integration is a process of reciprocal market opening, the present paper extends these authors' analysis, which focuses on the effects of unregulated

4. For instance, in 2009, the electricity ministry of Iraq announced that it could not pay the $\$ 2.4$ billion bill to G.E.; hence, power production would stop (Attwood 2009). In Madagascar, the Enelec firm decreased its provision of electricity to the public distributor company Jirama, leading to a power shortage due to billions in unpaid bills (Navalona 2012). In Zimbabwe, the utility Zesa Holdings failed to pay for electricity imports due to US $\$ 537$ million in unpaid electricity bills (The Herald 2011).

5. For instance, in December 2003, the members of the Economic Community of West African States (ECOWAS) signed the ECOWAS Energy Protocol, which calls for the elimination of cross-border barriers to trade in energy. The project, known as the West African Power Pool (WAPP), began with Nigeria, Benin, Togo, Ghana, Côte d'Ivoire, Burkina Faso, and Niger because these countries were already interconnected.

6. Caillaud 1990 studies a regulated market in which a dominant incumbent is exposed to competition from an unregulated, competitive fringe that is pricing at marginal cost. Biglaiser and Ma 1995 extend the analysis to a case in which a dominant regulated firm is exposed to competition from a single strategic competitor. Allowing for horizontal and vertical differentiation, these authors find that competition helps to extract the information rent of the regulated firm, but allocative inefficiency arises in equilibrium. 
competition in a closed economy, to a case in which the unregulated entrant is the incumbent of the foreign market. Considering both countries simultaneously permits the black box of sectorial integration in non-competitive industries to be opened. This analysis will help us to predict cases in which this integration is likely to be successful and those in which it is doomed to fail.

We show that the integration of power markets is welfare enhancing for both countries when the cost difference between the two regions is sufficiently large. For the low-cost region, the benefits from increased export profit (due to the possibility of also serving foreign demand) increase the total welfare in the exporting country. For the high-cost region, the domestic market benefits from the reduction in price caused by importation, which enhances consumer surplus. ${ }^{7}$ In contrast, sectorial integration is not likely to occur if the cost difference between the two countries is small. Indeed, unregulated competition tends to undermine the tax base (see Armstrong and Sappington 2005). Without a significant technological gap, competition for market share is fierce between the two countries, and thus, the negative business stealing outweighs the gain from trade. In contrast to the literature on trade subsidization policies (see Brander 1997), welfare may decrease in both regions following integration. All countries may lose, even in the absence of sizeable transportation costs and/or non-convexities. ${ }^{8}$

This paper next studies the impact of regional integration on countries' incentives to invest in new infrastructure. The paper distinguishes a cost-reducing investment (e.g., a new generation facility) from an investment in interconnection infrastructure (e.g., high voltage links). Compared to autarky, market integration improves incentives to invest in generation. First, when one country is much more efficient than another, a case in which integration is particularly appealing, the level of sustainable investment increases with regional integration. Integration remains suboptimal because the country endowed with the low-cost technology does not fully internalize the foreign country's consumer surplus (i.e., it only internalizes sales), but it increases compared to autarky. Moreover, incentives to invest in obsolete technology decrease, whereas incentives to invest in efficient technology increase. Second, when the two countries' technologies are similar, the firms must fight for their market shares and may thus overinvest in generation compared to the optimal solution. In practice, this risk of overinvestment is nil. First, the countries will resist the creation of a power pool if their cost difference is not large enough. Second, developing countries suffer

7. Even if the efficiency gains from integration are large enough so that both countries win from integration, opposition might persist internally because when production is reallocated toward more efficient providers, trade liberalization creates winners and losers internally.

8. This finding differs strikingly from the results in the trade literature. Starting with Brander and Spencer 1983, a portion of this literature has focused on the strategic effect of trade subsidization policies. These policies have a rent-shifting effect that creates a prisoner's dilemma, so firms benefit from jointly reducing the subsidies. However, even if the benefit from trade is lower, it is always positive. Similarly, in models à la Brander and Krugman 1983, welfare loss cannot occur with trade unless transportation costs are very high or there are non-convexities (see Markusen 1981). 
from massive underinvestment in generation. By stimulating investment, market integration can alleviate this problem.

In contrast, there is a major risk of underinvestment in infrastructures that constitute a public good, such as interconnection or transportation facilities. Free-riding behavior reduces incentives to invest, and business stealing reduces the capacity to finance new investment, especially in the importing country. The problem is sometimes so severe that global investment decreases compared to autarky. In other words, when the firms' generation costs are too close, the maximal level of investment in public-good facilities is not only suboptimal but is also smaller than in autarky. In practice, this risk is limited because the inefficient country will resist integration when the generation costs are too close. However, even if the gap between the costs is large enough that integration benefits both countries, the investment level in the public good components of the network will remain suboptimal. This structural underinvestment problem has important policy implications. Several programs supported by the World Bank in Bangladesh, Pakistan, and Sri Lanka have failed because they failed to address the interconnection problem. The World Bank supported lending to generators through the Energy Fund in the spirit of Public Private Partnerships. An investment in generation was made, and the production of kilowatts rose. However, due to poor transmission and distribution infrastructures, the plants were kept well below efficient production levels. On the one hand, power consumption stagnated because power was largely stuck at the production sites. On the other hand, public subsidies to the industry increased because take-or-pay Power Purchase Agreements had been used to commit to generation investment (see Manibog and Wegner 2003). Ultimately, both consumers and taxpayers were worse off.

Section I of the paper presents the model and the benchmark of a closed economy. Section II studies sectoral integration, and Section III focuses on countries' incentives to invest in generation and transportation infrastructure. Finally, Section IV offers some concluding remarks.

\section{A Model of Sectorial Integration With Independenthy REGULATED FIRMS}

We consider two symmetrical countries, identified by $i=1,2$. The inverse demand in each country is provided by ${ }^{9}$

$$
p_{i}=d-Q_{i}
$$

where $Q_{i}$ is the home demand in country $i=1,2$. The demand symmetry assumption is made to ease the exposition. Appendix $G$ shows that our primary

9. For the use of linear demand models in international oligopoly contexts, see Neary 2003, who also discusses the interpretation of these models and their extension to a general equilibrium framework. 
results are robust to asymmetric demands (i.e., different $d_{1} \neq d_{2}$ ). Before market integration, there is a monopoly in each country. In a closed economy, $Q_{i}$ corresponds to $q_{i}$, the quantity produced by the national monopoly, also identified by $i \in\{1,2\}$. When the markets are integrated, $Q_{i}$ can be produced by both firms 1 and 2 (i.e., $Q_{i}=q_{i i}+q_{j i}, i \neq j$, where $q_{i j}$, is the quantity sold by firm $i$ in country $j$ ). The total demand in the integrated market is given by

$$
p=d-\frac{Q}{2}
$$

where $Q=Q_{1}+Q_{2}$ is the total demand in the integrated market, which can be satisfied by firm 1 or 2 (i.e., $Q=q_{1}+q_{2}$ ).

On the production side, firm $i=1,2$ incurs a fixed cost that measures the economies of scale in the industry. The fixed cost is sunk, so it does not play a role in the optimal production choices. ${ }^{10}$ We thus avoid introducing new notation for this sunk cost.

The firm also incurs a variable cost function provided by

$$
c\left(\theta_{i}, q_{i}\right)=\theta_{i} q_{i}+\gamma \frac{q_{i}^{2}}{2}
$$

The variable cost function includes both a linear term $\theta_{i} \in[\underline{\theta}, \bar{\theta}]$, which represents the production cost, and an additional quadratic term, weighted by $\gamma$, which represents a transportation cost. The cost function (3) can be generated from a horizontal differentiation model à la Hotelling with a linear transportation cost in which Firm 1 is located at the left extremity and Firm 2 is at the right extremity of the unit interval. The linear market is first separated in two contiguous segments (the "national markets"). Market integration corresponds to the unification of the two segments. The common market is then represented by the full Hotelling line. To serve consumers, firms, which sell the good at a uniform price, must cover the transportation cost. This Hotelling model generates the cost function in (3), allowing the interpretation of $\gamma$ as a transportation cost (see Auriol 1998). ${ }^{11}$

The model assumes that the cost is increasing with the distance between the producer and the consumer. This assumption is legitimate in the electricity example because of the Joule effect and the associated transport charges and losses. Moreover, in the interconnected network, the transportation cost $\gamma$ is the same for both domestic and international consumers. This assumption is also

10. Because the cost is already sunk at the time that the countries choose whether to integrate and their production levels, it does not play a role in their decision.

11. In other words, assume that the consumers are uniformly distributed over $[0,1]$. To deliver one unit to a consumer located at $q \in[0,1]$, the transportation cost is $\gamma q$ for firm 1 and $\gamma(1-q)$ for firm 2 . The variable production cost of firm $i$ with market share equal to $q_{i}$ can then be written as $c\left(\theta_{i}, q_{i}\right)=\int_{0}^{q_{i}}\left(\theta_{i}+\gamma q\right) \mathrm{d} q$, or equivalently $c\left(\theta_{i}, q_{i}\right)=\theta_{i} q_{i}+\gamma\left(q_{i}^{2} / 2\right)(i=1,2)$. 
consistent with the physical characteristics of electric networks. This physical unity, which comes from the fact that electricity cannot be routed, is what differentiates electric systems from other systems of distribution of goods and services. ${ }^{12}$

In summary, $\theta_{i} \in[\underline{\theta}, \bar{\theta}]$ can be interpreted as a generation cost that is constant after some fixed investment has been performed, whereas $\gamma$ is a measure of transportation costs (i.e., transport charges and losses). In the following, we assume that $\gamma$ and $\theta_{i}$ are common knowledge. Any distortions occurring at equilibrium can thus be ascribed to a coordination failure between the national regulators. However, our results are robust to the assumption of asymmetric information on these parameters. ${ }^{13}$ To rule out corner solutions, we make the following assumption:

A0 $\quad d>\bar{\theta}$.

Assumption $\mathrm{A} 0$ ensures that in equilibrium, the quantities are strictly positive. The profit of firm $i=1,2$ is

$$
\Pi_{i}=P(Q) q_{i}-\theta_{i} q_{i}-\gamma \frac{q_{i}^{2}}{2}-t_{i}
$$

where $t_{i}$ is the tax that the firm pays to the government (it is a subsidy if it is negative). The participation constraint of the regulated firm is

$$
\Pi_{i} \geq 0
$$

The regulator of country $i$ has jurisdiction over the national monopoly $i$. She regulates the quantities and the investments of the firm and is allowed to transfer funds to and from the firm, and she taxes operating profits when they are positive and subsidizes losses. This process is consistent with public ownership. In the case of electricity, public and mixed firms are key players in most developing countries: in 2004, $60 \%$ of the less developed countries had no significant private participation in electricity (Estache, Perelman, and Trujillo 2005). ${ }^{14}$

12. For more details on the specificities of electric markets, see Joskow and Schmalensee 1985.

13. Because $\gamma$ is a common value, the regulator can implement some yardstick competition to freely learn its value in the case of asymmetric information. In contrast, if the regulator does not observe the independent cost parameter $\theta_{\mathrm{i}}$, some rent must be abandoned to the producer to extract this information. The cost parameter is replaced by the virtual cost (i.e., the production cost plus the information rent, $\theta_{i}+\Lambda F\left(\theta_{i}\right) / f\left(\theta_{i}\right)$, where $f$ and $F$ are the density and repartition functions of $\left.\theta_{\mathrm{i}}\right)$. Introducing asymmetric information does not change our primary results except for the inflated cost parameter (computations available upon request). In the event that a supranational regulator is created, the impact of asymmetric information will depend on the supranational regulator's ability to gather information on the firms as compared to the national regulators.

14. This lack of private participation also exists in many advanced economies. For instance, $87.3 \%$ of Electricite de France (EDF), which is one of the largest exporters of electricity in the world, is owned by the French government. In 2007, the firm paid over EUR 2.4 billion in dividends to the government. 
In contrast, rent extraction does not apply to foreign firms because they do not report their profits locally. The regulator does not seize the rent of foreign firm and does not have to subsidize the losses. Moreover, the regulator of country $i$ does not control the production or the investment of firm $j$ (i.e., asymmetric regulation).

Each utilitarian regulator in country $i$ maximizes the home welfare, $W_{i}=S\left(Q_{i}\right)-P(Q) Q_{i}+\Pi_{i}+(1+\lambda) t_{i}$, where $S\left(Q_{i}\right)=\int_{0}^{Q_{i}} p_{i}(Q) \mathrm{d} Q=d Q_{i}-Q_{i}^{2} / 2$ is the gross consumer surplus, $\Pi_{i}$ is the profit of the national firm, and $(1+\lambda) t_{i}$ is the opportunity cost of public transfers. Because $W_{i}$ is decreasing in $\Pi_{i}$ when $\lambda \geq 0$, leaving rents to the monopoly is socially costly. The participation constraint of the national firm (5) always binds: $\Pi_{i}=0 .{ }^{15}$ The utilitarian welfare function in country $i=1,2$ is

$$
W_{i}=S\left(Q_{i}\right)-P(Q) Q_{i}+(1+\lambda) P(Q) q_{i}-(1+\lambda)\left(\theta_{i} q_{i}+\gamma \frac{q_{i}^{2}}{2}\right)
$$

The regulator of country $i$ is not indifferent between producing power locally (i.e., $q_{i}$ ) and importing it (i.e., $Q_{i}-q_{i}$ ). She is biased in favor of local production. This national preference, which is consistent with countries' objective of energy independence, reflects the fact that the regulator is the residual claimant for the firm profit and loss. The bias increases with $\lambda \geq 0$, which can be interpreted as the shadow price of the government budget constraint (i.e., the Lagrange multiplier of this constraint). ${ }^{16}$ Any additional investment in public utilities implies a reduction in the production of essential public goods or in any other commodities that generate positive externalities, such as health care. Additional investment may also imply an increase in taxes or public debt. All of these actions have a social cost that must be compared with the social benefit of the additional investment. Conversely, when the transfer is positive (i.e., taxes on profits), it helps to reduce distortionary taxation or to finance investment. The assumption of costly public funds is a way to capture the general equilibrium effects of sectoral intervention. To avoid introducing bias into the integration decision, we assume that both countries have the same cost of public funds, $\lambda$.

15. Here, regulation is effective (there is no problem from reducing the monopoly power in the closed economy). We thus abstract from a possible alternative motivation for integration as a way to reduce the market power of the incumbent.

16. The government pursues multiple objectives, such as producing public goods, regulating noncompetitive industries, and controlling externalities, under a single budget constraint. The opportunity cost of public funds indicates how much social welfare can be improved when the budget constraint is relaxed marginally; it includes the forgone benefits of alternative investment choices and spending. In advanced economies, $\lambda$ is usually estimated at approximately 0.3 (Snow and Warren 1996). In developing countries, low income levels and difficulty implementing effective taxation imply higher values for $\lambda$. The World Bank 1998 suggests an opportunity cost of 0.9 as a benchmark, but it may be much higher in heavily indebted countries. 
In the following, we express the results in terms of $\Lambda$, which increases with $\lambda \in[0,+\infty):$

$$
\Lambda=\frac{\lambda}{1+\lambda} \in[0,1]
$$

We first briefly describe the case of a closed economy, marked C. Each regulator maximizes the expected national welfare (6) subject to the autarky production condition $Q_{i}=q_{i}$. The optimal autarky quantity is

$$
q_{i}^{C}=\frac{d-\theta_{i}}{1+\gamma+\Lambda}
$$

When $\Lambda=0$, public funds are costless, and the price is equal to the marginal cost $P\left(q_{i}^{C}\right)=\theta_{i}+\gamma q_{i}^{C}$. When $\Lambda>0$, the price is raised above the marginal cost with a rule that is inversely proportional to the elasticity of demand (Ramsey pricing): $P\left(q_{i}^{C}\right)=\theta_{i}+\gamma q_{i}^{C}+\Lambda P\left(q_{i}^{C}\right) / \varepsilon$. The optimal pricing rule diverges from marginal cost pricing in proportion to the opportunity cost of public fund $\Lambda$ because the revenue of the regulated firm allows the level of other transfers in the economy (and thus distortive taxation) to be decreased.

The closed economy case corresponds to a pure autarky model in which the electricity is distributed and produced internally. Alternatively, we could consider other forms for the import and export of energy without the formation of a power pool or the existence of a free trade agreement. In this case, countries could negotiate to import a certain quantity of electricity from abroad (at a given price) and then sell it internally at the regulated price. This strategy differs from the integrated case studied below because the regulator would be able to control the total quantity sold in the internal market. For the national regulator, this case of negotiated import (or equivalently regulated import quotas) boils down to a problem of production allocation over two plants with different cost functions (one plant would be the national producer and the other the import possibility). This case would lead to a different (lower) aggregate cost function. Nevertheless, the regulator would still choose the total quantity sold in the market. Given the demand and the new cost function, she would determine a Ramsey price that is similar to that described above. This solution, which does not differ qualitatively from autarky, would allow a superior foreign technology to be exploited without incurring the coordination problems related to business stealing.

In practice, import agreements of this type remain small in size and do not constitute a valid solution to the capacity shortage faced by most developing countries because these agreements do not stimulate investment. The complexity and financial commitments demanded by international electricity trade projects require a level of coordination among the parties that cannot be achieved by a simple ex-post purchase agreement. The creation of a power pool encourages 
investment in the energy sector by providing international arbitration for dispute resolution, the repatriation of profits, protection against the expropriation of assets, and other terms that are considered attractive by potential investors. The next section studies the impact of the creation of an integrated power pool on energy production.

\section{Common Power Pool}

When barriers to trade in the power market are removed, firms can serve consumers in both countries so that there is a single price. The demand functions are symmetric, which implies that the level of consumption is the same in the two countries: $Q_{i}=(1 / 2) Q^{O}, i=1,2$. In contrast, the generation cost functions are different, which implies a different level of production in the two countries. We first consider the solution that would be chosen by a global welfare-maximizing social planner. This theoretical benchmark describes a process of integration in which the two countries are fully integrated politically and fiscally. We then consider sectorial integration with two independent regulators. Finally, we perform a welfare analysis and determine the distributive impact of integration.

\section{Full Integration}

The supranational utilitarian social planner has no national preferences. He maximizes $W=W_{1}+W_{2}$, the sum of welfare functions defined in (6),

$$
W=S\left(Q_{1}\right)+S\left(Q_{2}\right)+\lambda P(Q) Q-(1+\lambda)\left(\theta_{1} q_{1}+\gamma \frac{q_{1}^{2}}{2}+\theta_{2} q_{2}+\gamma \frac{q_{2}^{2}}{2}\right)
$$

with respect to quantities $\left(Q_{1}, Q_{2}, q_{1}, q_{2}\right)$, under the constraint that consumption $Q=Q_{1}+Q_{2}$ equals production $q=q_{1}+q_{2}$. This problem can be solved sequentially. First, the optimal consumption sharing rule between the two countries $\left(Q_{1}, Q_{2}\right)$ is computed for any level of production $q$. This calculation maximizes $S\left(Q_{1}\right)+S\left(Q_{2}\right)$ under the constraint that $Q_{1}+Q_{2}=q_{1}+q_{2}$. Because $S\left(Q_{i}\right)=d Q_{i}-Q_{i}^{2} / 2$, we easily deduce that the optimal consumption allocations are $Q_{1}=Q_{2}=\left(Q_{1}+Q_{2}\right) / 2$. Hence, the supranational utilitarian objective function (9) becomes

$$
W=2 S\left(\frac{q_{1}+q_{2}}{2}\right)+\lambda P\left(q_{1}+q_{2}\right)\left(q_{1}+q_{2}\right)-(1+\lambda)\left(\theta_{1} q_{1}+\gamma \frac{q_{1}^{2}}{2}+\theta_{2} q_{2}+\gamma \frac{q_{2}^{2}}{2}\right)
$$

Let $\theta_{\min }=\min \left\{\theta_{1}, \theta_{2}\right\}$ and $\Delta=\theta_{2}-\theta_{1}$, which can be positive or negative. Second, (10) is optimized with respect to the quantities $q_{1}$ and $q_{2}$. 


\section{Proposition 1}

The socially optimal quantity is

$$
Q^{*}=\left\{\begin{array}{cc}
\frac{2}{1+\Lambda+2 \gamma}\left(d-\theta_{\min }\right) & \text { by monopoly if }|\Delta|>\Delta^{*}=\frac{2 \gamma\left(d-\theta_{\min }\right)}{1+2 \gamma+\Lambda} \\
\frac{2}{1+\Lambda+\gamma}\left(d-\frac{\theta_{1}+\theta_{2}}{2}\right) & \text { by duopoly } i=1,2 \text { with } \\
& q_{i}^{*}=\frac{Q^{*}}{2}+\frac{\theta_{j}-\theta_{i}}{2 \gamma} \text { otherwise. }
\end{array}\right.
$$

See Appendix A for the proof.

When the cost difference between the two firms is large (i.e., when $|\Delta|>\Delta^{*}$ ), the less efficient producer is shut down, and the most efficient firm is in a monopoly position. This result implies that when there is no transportation cost (i.e., $\gamma=0$ ), the first best contract always prescribes the shut down of the less efficient firm. However the "shut down" result is upset with the introduction of a transportation cost. When $\gamma$ is positive, both firms produce whenever $|\Delta| \leq \Delta^{*}$. The most efficient firm (i.e., the firm with the cost parameter $\theta_{\min }$ ) has a larger market share than its competitor (see (11)). However, the market share differences decrease with $\gamma$.

In practice, sectorial integration generally excludes fiscal and political institutions, which remain decentralized at the country level. ${ }^{17}$ Sovereign governments and regulators do not share profits and tariff revenues among themselves. Taxpayers enjoy taxation by regulation insofar as the rents come from their national firms. The next section studies the distortions induced by the noncooperative equilibrium between two governments. ${ }^{18}$

\section{Sectorial Integration with Asymmetric Regulation}

In the case of sectoral integration, marked $O$, national regulators simultaneously fix the quantity produced by the national firm, $q_{i}^{O}$, maximizing national welfare (6). The reaction functions of the regulators determine the non-cooperative equilibrium.

17. The fusion of regulatory bodies and fiscal systems is rarely achieved. The German reunification, with the East and West German economic systems unified under the same government, is an exception. Consistent with the theory, many firms have been shut down in East Germany. The reallocation of production toward more efficient units has been sustained by transfers from West Germany.

18. If governments could bargain efficiently among themselves, the optimal solution to Proposition 1 could be achieved. The problem is that the Coase solution requires zero transaction costs to hold. In the context of two developing countries, efficient bargaining over enormous investments is not a realistic assumption. Because developing countries are plagued with weak property rights and rule of law, significant corruption, and inefficient justice systems, transaction costs are higher in developing countries than in advanced economies. In practice, we do not observe efficient bargaining in either type of country, but the inefficiencies are worse in developing countries. 


\section{Proposition 2}

The quantity produced at the non-cooperative equilibrium of the sectorial integration game is

$$
Q^{O}=\left\{\begin{array}{cc}
\frac{4}{3+4 \gamma+\Lambda}\left(d-\theta_{\min }\right) & \text { by monopoly if }|\Delta| \geq \Delta^{O}=\frac{2(1+2 \gamma)\left(d-\theta_{\min }\right)}{3+4 \gamma+\Lambda} \\
\frac{4}{2+2 \gamma+\Lambda}\left(d-\frac{\theta_{1}+\theta_{2}}{2}\right) & \text { by duopoly } i=1,2 \text { with } \\
& q_{i}^{O}=\frac{Q^{O}}{2}+\frac{\theta_{j}-\theta_{i}}{1+2 \gamma} \text { otherwise }
\end{array}\right.
$$

See Appendix B for proof.

Comparing equations (12) and (11), the equilibrium solution implies that the closure of the less efficient firm occurs less often than in the socially optimal solution. That is, $\Delta^{\mathrm{O}} \geq \Delta^{*}$ under assumption A0.

Comparing the common market with the closed economy case, it is straightforward to check that $Q^{O}$ defined in equation (12) is always larger than $Q^{C}=q_{1}^{C}+q_{2}^{C}$ defined in equation (8). The fact that the total quantity increases under market integration does not necessarily imply a welfare improvement. Indeed, when $|\Delta| \leq \Delta^{*}$, we have that $Q^{C}=Q^{*}$ defined in equation (11). We deduce that excessive production occurs in the common market. To be more specific, comparing $Q^{O}$ and $Q^{*}$ yields

$$
Q^{O} \geq Q^{*} \Leftrightarrow|\Delta| \leq \Delta^{O / *}=\frac{(2 \gamma+\Lambda)\left(d-\theta_{\min }\right)}{1+2 \gamma+\Lambda} .
$$

When $|\Delta|$ is smaller than $\Delta^{\mathrm{O} / *}$, the regulators fight to maintain their market shares by boosting domestic production. Aggregate quantities are then larger in the common market than at the optimum. In a closed economy, the regulator with the less efficient technology chooses a small quantity to enjoy a high Ramsey margin. However, in the open economy, the Ramsey margin is eroded by competition, and producing such a small quantity is no longer optimal; it only reduces the market share of the domestic firm. In his attempt to mitigate the business stealing effect, the regulator increases the quantity of the domestic firm so that $Q^{O}>Q^{*} \cdot{ }^{19}$ Symmetrically, when $|\Delta|$ is larger than $\Delta^{\mathrm{O} / *}$, the regulator of the most efficient country controls a large market share (the firm even becomes a monopolist in the common market when $|\Delta|>\Delta^{O}$ ). The problem is that the

19. Substituting $Q^{O}$ from equation (12) into market share equation $q_{i}^{O}$ and comparing it with equation (8) yields $q_{i}^{\mathrm{O}}>q_{i}^{\mathrm{C}} \Leftrightarrow \theta_{j}-\theta_{i} \geq-\Lambda\left(d-\theta_{i}\right)(1+\gamma) /(1+\gamma+\Lambda)^{2} j \neq i i=1,2$. A regulator might choose to expand the national quantity with respect to the quantity produced in a closed economy even if the competitor is slightly more efficient. The reason for this choice is that competition decreases the net profits of the national firm without generating a drastic increase in the consumers' surplus. 
FIGURE 1. Welfare Gains from Integration, $W_{1}^{O}-W_{1}^{C}$
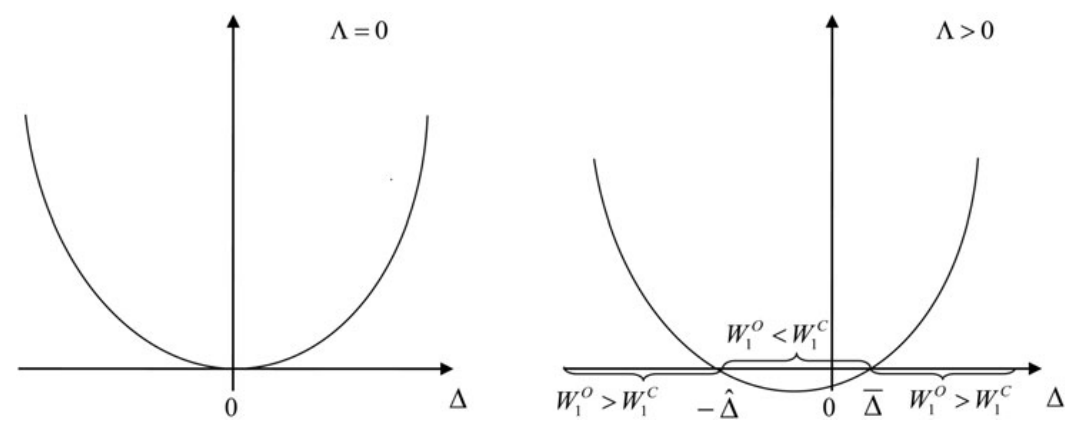

regulator does not internalize the welfare of foreign consumers. She chooses a suboptimal production level $Q^{O}<Q^{*}$.

\section{The Political Economy of Sectorial Integration}

Even if one country has lower generation costs than the other, competition for the rents of the sector yields inefficiencies that might prevent sectorial integration. Both countries must win from the creation of a common power pool for the integration to occur. Replacing the optimal quantities in the welfare function, we show the following result.

\section{Proposition 3}

For any $\Lambda$ that is strictly positive, market integration increases welfare in both countries if and only if the difference in the marginal costs $|\Delta|$ is large enough.

See Appendix C for proof.

Figure 1 illustrates Proposition 3. The figure contrasts the welfare gains of country 1 for $\Lambda>0$ with the welfare gains of country 1 for $\Lambda=0$. When $\Lambda=0$, taxation by regulation is not an issue, and an increase in $|\Delta|$ increases the welfare gains identically in the low- and high-cost countries. The less efficient country enjoys a lower price, whereas the more efficient country enjoys higher profits. Business stealing creates no loss because it is compensated by an increase in the consumer surplus in the country with a smaller market share. However, the equilibrium quantities (12) do not correspond with the optimal levels (11) because not all gains from trade are exploited. The results are modified when $\Lambda>0$. When $\Lambda>0$, the intercept corresponding to $\Delta=0$, is negative, which means that if $\theta_{1}=\theta_{2}$, both countries lose from integration. To fight business stealing, both countries increase their quantities. The price is decreased below the optimal monopoly Ramsey level, and taxation by regulation decreases (or, alternatively, subsidies increase). However, competition does not increase efficiency because the firms have the same cost. The net welfare impact is negative for both countries. For $\Delta \neq 0$, the welfare gains of the two countries are asymmetric. For the most efficient country, the gains 
are strictly increasing. For the less efficient country, they are U-shaped. For a large enough $|\Delta|$, the welfare gains are positive in both countries.

The country with the less efficient technology generally has lower gains from integration $(\hat{\Delta} \geq \bar{\Delta})$. The level of gains depends on the adverse effect of business stealing on the budget constraint of the less efficient firm, which will in general receive a higher transfer (or pay lower taxes) in the common market. It is clear that for a $\Delta$ belonging to the interval $[-\bar{\Delta}, \bar{\Delta}]$, the creation of a power pool managed by two independent regulators is inefficient. Each country's welfare is decreased by integration. The region as a whole is better off with the co-existence of two separate markets. This result is not related to the assumption of limited competition (i.e., duopoly). Increasing the number of unregulated competitors, including a foreign firm reporting its profit in a third country, would only worsen the negative business stealing. Similarly, a laissez-faire policy would not suppress the welfare losses related to business stealing. ${ }^{20}$

For values of $|\Delta| \in[\bar{\Delta}, \hat{\Delta}]$, the most efficient country wins, and the less efficient country loses. If one region loses and the other wins, there will be resistance to integration. In contrast, welfare increases in both countries for values of $\Delta$ smaller than $-\hat{\Delta}$ and larger than $\hat{\Delta}$ despite the uncoordinated policies. In other words, the theory predicts that integration will be easier to achieve when the cost difference between the two countries is large.

In addition to the global welfare impact, the creation of an integrated market with a common price $P\left(Q^{O}\right)$ has redistributive effects. To see this point, let us focus on $|\Delta| \leq \Delta^{O}$. Consider first the case in which the gap in firms' costs is so that $\Delta^{O} \geq|\Delta|>\left(\Lambda\left(d-\theta_{\min }\right)\right) /(1+\gamma+\Lambda) .^{21}$ In this case, market integration induces a price reduction in the less efficient region and a price increase in the more efficient one. Consumers from the relatively efficient region are thus worse off after integration, which may be a source of social discontent and opposition toward sectorial integration. The interests of the national firm/taxpayers conflict with the interests of the domestic consumers. ${ }^{22}$ If the government is unable to seize firm's rents, both domestic taxpayers and consumers are worse off (shareholders are the only winners).

In contrast, if the firms are not drastically different (i.e., if $|\Delta| \leq \Lambda\left(d-\theta_{\min }\right) /(1+\gamma+\Lambda)$, prices decrease in both countries because of the

20. The trade and competition literature shows that when firms are identical, the welfare losses can be reduced by jointly banning the subsidies and committing to a laissez-faire policy (Brander and Spencer 1983; Collie 2000). When firms are identical, we obtain similar results for some values of $\Lambda$ (as in Collie 2000). However, this result is not robust to the assumption of heterogeneous firms.

21. Since $|\Delta| \leq \Delta^{O}$ there is a duopoly after integration. Substituting $Q^{O}$ from equation (12) in the inverse demand function yields the equilibrium price $P\left(Q^{O}\right)=\left(d(\Lambda / 2+\gamma)+\left(\theta_{1}+\theta_{2}\right) / 2\right) /(1+\gamma+\Lambda / 2)$ if $|\Delta| \leq \Delta^{O}$. Comparing this price with the price in the closed economy, $P\left(q_{i}^{c}\right)=\left(\theta_{i}+(\Lambda+\gamma)\left(d-\theta_{i}\right)\right) /$ $(1+\gamma+\Lambda)$ we obtain that the price increases in country $i=1,2$ if and only if $\theta_{j}-\theta_{i} \geq$ $\left(\Lambda\left(d-\theta_{i}\right)\right) /(1+\gamma+\Lambda) \geq 0$. Letting $\theta_{\min }=\min \left\{\theta_{1}, \theta_{2}\right\}$ and $|\Delta \|=| \theta_{2}-\theta_{1} \mid$ yields the result.

22. In the international trade literature, a similar conflict of interest arises between domestic producers and consumers (see Feenstra, 2008). 
business stealing effect. Benevolent regulators are willing to increase their transfers to the national firm to sustain low prices so that taxation by regulation decreases, harming taxpayers and the total welfare. The negative fiscal effect is a major concern in developing countries, where tariffs play an important role in raising funds (see Laffont, 2005, and Auriol and Picard, 2006). When public funds are scarce and other sources of taxation are distortionary or limited, market integration, which has a negative impact on taxpayers and on industries' ability to finance new investments, induces welfare losses.

Our welfare analysis is conducted under several simplifying assumptions that should be discussed. First, we focus on asymmetry in costs. However, countries may differ in other dimensions. In particular, they may have different market sizes (i.e., $d_{1} \neq d_{2}$ ). We explore this possibility in Appendix G. Because of the quadratic transportation costs, a smaller country has a smaller marginal cost in a closed economy. Market integration generates additional efficiency gains by reallocating production toward the producers that initially had the smaller internal demand. We show in the appendix that the smallest country always wins more from integration than the largest one. This result is consistent with the finding in the international trade literature that smaller economies tend to gain more from trade in oligopolistic markets than large economies (see Markusen, 1981). Appendix $G$ also shows that our primary result is robust: sectoral integration is welfare degrading if countries are too similar (i.e., in cost and in demand).

Second, one could decide that the inefficiency result yielded by sectoral integration is related to the limited set of tax instruments used by the regulator. We concentrate on the profit taxation of regulated firms, and we do not study the possibility of introducing additional taxes (e.g., a general tax on consumers such as a VAT or a tax on transport or distribution). In a closed economy, this focus does not incur a loss of generality because there is no need for additional taxes when it is possible to fix both the price and the tax on total industry profits. In the integrated market, this irrelevance result does not hold because the national regulator is unable to tax the importing firm's profit or to control its offer. Competition for market share erodes the national firm's profit and thus the possibility of taxation. Assuming that new instruments are introduced, if the regulator is allowed to use different tax rates on foreign and domestic firms, she will be able to influence the volume of import. The regulator uses the tax structure to reduce the market share of the foreign firm whenever it does not bring enough efficiency gains (i.e., by reducing the market share of the competitor in such a way that it does not "steal" demand with respect to autarky). However, this type of asymmetric treatment is incompatible with the creation of an integrated electricity market aimed at promoting investment. Investors must believe that they will be able to sell their production in the foreign market without facing the ex-post threat of abusive taxation or other hold-up problems. In this case, the regulator is obliged to apply the same tax rate to local and foreign firms. Adding taxes on the volume of transactions could be used to generate income on the activities of the foreign firm and to influence its scale of production. In addition to greatly 
complicating the model resolution, this form of taxation cannot restore efficiency. The heart of the problem is not the nature of the tax instrument used to collect revenue and influence production but rather that each firm's profits (and the consumer surplus) are accounted for locally. ${ }^{23}$ This creates an asymmetry (i.e., a national preference) between the valuation of local and foreign production, which is at the heart of the inefficiency result.

\section{INVESTMENT}

Proponents of regional power pools claim that by fostering the emergence of a larger market, the pools will stimulate investment. However, it is not clear that the model of integration favored by international aid agencies provides an adequate framework for investment incentives. Unless the cost difference between two regions is sufficiently large, market integration with asymmetric regulation may decrease total welfare and thus may undermine the global capacity to finance new investment. Our analysis focuses on two types of investment. The first type reduces the production cost of the investing firm (e.g., generation facilities). This investment is referred to as "production cost reducing" or " $\theta$-reducing" investment. This type only benefits the investing producer and makes the producer more aggressive in the common market. We assume that this investment is only possible in one country (by convention, country 1 ) because of the availability of a specific input or technology. Consider a dam: hydropower potentials (and natural resources such as oil or gas) are unevenly distributed across countries. Country 1 can reduce its production cost from $\theta_{1}$ to $\delta \theta_{1}(\delta<1)$ by investing a fixed amount $I_{\theta}$.

The second type of investment decreases the transportation cost $\gamma$. We refer to this type of investment as "transportation cost reducing" or " $\gamma$-reducing" investment. In the integrated market, the competitor of the investing firm also benefits from the investment. One can think of an investment in transmission, interconnection, or interoperability facilities. We assume that both countries can reduce the collective transportation cost from $\gamma$ to $s \gamma$ with $s \in(0,1)$ by investing a fixed amount $I_{\gamma}>0$.

For both types of investment, we focus on interior solutions. The cost difference is assumed to be small enough that the production of the two firms is positive in the common market. The following assumption ensures that there is no shut down in the first best case. ${ }^{24}$

$$
\left|\theta_{2}-\delta \theta_{1}\right| \leq \frac{2 s \gamma\left(d-\min \left\{\delta \theta_{1}, \theta_{2}\right\}\right)}{1+2 s \gamma+\Lambda} .
$$

23. To see this point more clearly, we focus on the case in which $\Lambda=0$, so fiscal issues are irrelevant for the regulators. Substituting $\Lambda=0$ in (13), one can easily check that the inefficiency in production levels remains. The equilibrium is always sub-optimal, and it is worse when $\Lambda>0$.

24. Assumption A1, which is the condition in equation (11) with $\Delta^{*}$ evaluated at $\delta \theta_{1}$ instead of $\theta_{1}$ and $s \gamma$ instead of $\gamma$, ensures that both firms produce in all possible cases. As illustrated by the analysis in Section 2, this assumption is not crucial, but it greatly simplifies the exposition. Our results are preserved when the shut-down cases are considered (computations are available on request). 


\section{Investment in Generation}

We begin by considering the solution induced by the global welfare maximizer in the case of a $\theta$-reducing investment by firm 1 . The optimal quantities, denoted $q_{i}^{* \mathrm{I}_{\theta}}(i=1,2)$, are provided by equations (11), where $\theta_{1}$ is replaced by $\delta \theta_{1}(\delta<1)$. Substituting the quantities $q_{i}^{* \mathrm{I}_{\theta}}(i=1,2)$ into the welfare function defines equation (10), and the gross utilitarian welfare is $W^{* \mathrm{I}_{\theta}}=W\left(q_{1}^{* \mathrm{I}_{\theta}}, q_{2}^{* \mathrm{I}_{\theta}}\right)$. The welfare gain of the investment $W^{* I_{\theta}}-W^{*}$ must be compared with the social cost of the investment $(1+\lambda) I_{\theta}$. The social cost of investment $I_{\theta}$ is weighted by the opportunity cost of public funds because devoting resources to investment decreases the firm's operating profit and the government's revenue by $I_{\theta}$, which has an opportunity cost of $1+\lambda$. The global welfare maximizer regulator invests if and only if $W^{* I_{\theta}}-W^{*} \geq(1+\lambda) I_{\theta}$. Let us denote $I_{\theta}^{*}$ as the maximal level of investment that satisfies this inequality:

$$
I_{\theta}^{*}=\frac{1}{1+\lambda}\left[W^{* I_{\theta}}-W^{*}\right]
$$

The non-cooperative equilibrium quantities in the case of sectoral integration, $q_{i}^{\mathrm{OI}}$, and the quantities in the case of a closed economy, $q_{i}^{C I_{\theta}}$, are derived using a similar method from the equations (12) and (8), respectively, where $\theta_{1}$ is replaced by $\delta \theta_{1}$. Substituting the quantities $q_{i}^{k I_{\theta}}(i=1,2$ and $k=O, C)$ in the welfare function of the country 1 defined in equation (6), the regulator of country 1 invests if and only if $W_{1}^{k I_{\theta}}-W_{1}^{k} \geq(1+\lambda) I_{\theta}$. We deduce the maximal level of investment that country 1 is willing to commit in the common market and in the closed economy:

$$
I_{\theta}^{k}=\frac{1}{1+\lambda}\left[W_{1}^{k I_{\theta}}-W_{1}^{k}\right] \quad k=O, C
$$

The next proposition compares the different investment levels (i.e., when $k=*, O$, $C)$ as a function of the initial cost difference $\Delta=\theta_{2}-\theta_{1}$.

\section{Proposition 4}

Let $\Lambda>0, \delta \in(0,1)$ and $\Delta=\theta_{2}-\theta_{1}$. Let $I_{\theta}^{*}$ and $I_{\theta}^{k}(k=O, C)$ be defined in (14) and (15), respectively. There are three thresholds $\hat{\Delta}_{a}<\hat{\Delta}_{b}<\hat{\Delta}_{c}$, such that

- $I_{\theta}^{O}>I_{\theta}^{C} \Leftrightarrow 0>\Delta>\hat{\Delta}_{a}$.

- $I_{\theta}^{*}>I_{\theta}^{C} \Leftrightarrow 0>\Delta>\hat{\Delta}_{b}$.

- $I_{\theta}^{*}>I_{\theta}^{O} \Leftrightarrow \Delta>\hat{\Delta}_{c}$.

See Appendix D for proof.

Figure 2 illustrates the results of Proposition 4. The figure is drawn for a fixed value of $\delta \theta_{1}$. The static comparative parameter is $\Delta$. The flat line $I_{\theta}^{C}$ represents the autarky equilibrium level of investment for country 1 . This level is independent 
FIGURE 2. $\theta_{1}$-Reducing Investment

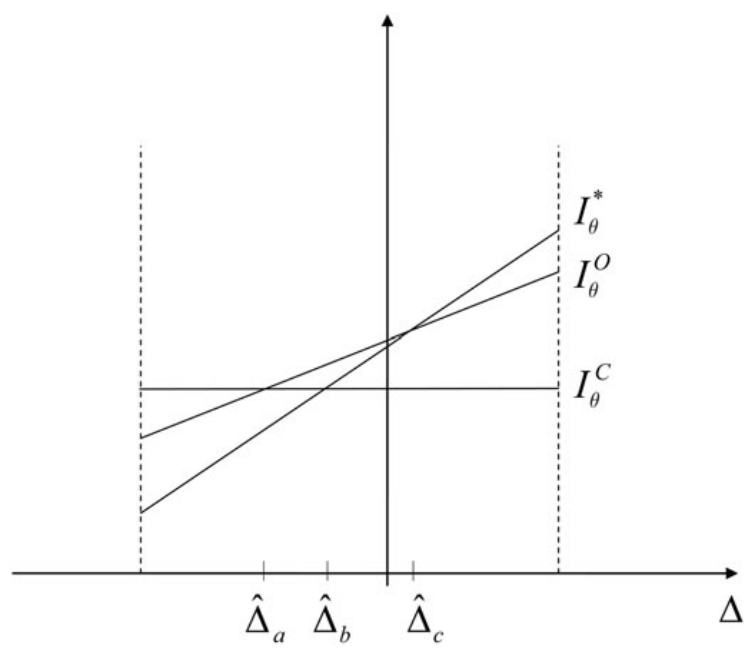

of the efficiency of firm 2 (i.e., it is independent of $\Delta$, hence the flat shape) because in the absence of trade, what happens in country 2 does not influence the investment choice of the regulator in country 1 . The line $I_{\theta}^{O}$ represents the equilibrium investment in the open market, and $I_{\theta}^{*}$ represents the optimal level. Both increase with $\Delta$ : the gains from trade and the incentives to invest are larger when the gap in generation costs is large.

One relevant policy question is whether economic integration can improve the autarky outcome. When $\Lambda=0$, business stealing has no adverse impact on national welfare, so $\hat{\Delta}_{a}=\hat{\Delta}_{b}=\hat{\Delta}_{c}=(1-\delta) \theta_{1} / 2$. In this case, market integration unambiguously reduces (without eliminating) the gap between the optimal and the equilibrium levels of investment. However, when $\Lambda>0$, the thresholds $\hat{\Delta}_{a}$ and $\hat{\Delta}_{c}$ shift to the left and to the right, respectively, whereas $\hat{\Delta}_{b}$ is not affected (see Appendix D). ${ }^{25}$ Theoretically, there are cases in which integration worsens the gap between the equilibrium investment level and the optimum.

To be more specific, Proposition 4 implies that market integration improves the situation with respect to autarky when the initial cost difference between the two regions is large. First, when $\Delta>\hat{\Delta}_{c}$, country 1 chooses a level of investment in autarky that is inefficiently low. The region is endowed with abundant resources (e.g., hydroelectric potential), but the investment $I_{\theta}^{O}$ is oversized for the domestic demand. Integration helps to increase the level of investment that country 1 is willing to sustain by enlarging its market size through access to foreign demand. In this case, the creation of a power pool moves the equilibrium

25. When $\Lambda$ increases, all thresholds $I_{\theta}^{O}, I_{\theta}^{*} I_{\theta}^{C}$ shift downward because the social cost of investment increases. However, $I_{\theta}^{O}$ has less of a decrease because investment becomes important to reduce the business stealing effect in the common market. As a result, the region of over-investment increases. 
investment closer to the optimal level $I_{\theta}^{*}$. However, it does not restore the first best level. When $\Delta>\hat{\Delta}_{c}$, the open market equilibrium of investment $I_{\theta}^{O}$ is lower than the optimal level $I_{\theta}^{*}$ because the investing country does not fully internalize the increase in the foreign consumer surplus (it only internalizes sales). Second, when $\Delta<\hat{\Delta}_{a}$, country 1 is very inefficient. ${ }^{26}$ In autarky, the only way to increase the level of consumption (and, thus, total welfare) is through a cost-reducing investment. Yet, in the open economy, this investment is a waste because the market can be served by the superior foreign technology. The creation of a power pool improves the situation by reducing the level of investment in obsolete technology. However, the power pool does not restore efficiency. The possibility of reducing the cost gap and expanding market share by serving foreign consumers makes a higher than optimal level of investment attractive (i.e., $I_{\theta}^{O}$ is higher than $I_{\theta}^{*}$ ).

For $\hat{\Delta}_{a}<\Delta<\hat{\Delta}_{b}$, the level of investment is inefficiently high under both a closed and an open economy. ${ }^{27}$ However, the over-investment problem is more severe in the open economy because of the business stealing problem. A production-cost reducing investment increases the relative efficiency of the national firm. The firm invests to strengthen its position in the common market and to reduce its competitive gap; it does not internalize the cost that it imposes on country 2 , and it overinvests. In this case, market integration worsens incentives to invest with respect to autarky. However, the values of $\Delta$ corresponding to this situation, $\left[\hat{\Delta}_{a}, \hat{\Delta}_{b}\right]$, are generally included in the interval $[-\hat{\Delta}, \bar{\Delta}]$ within which the country with the less efficient technology would not accept integration in the first place. $^{28}$ Therefore, unless the creation of a power pool is forced on the countries, it is very unlikely that this over-investment problem will arise in equilibrium. In practice, developing countries face a chronic underinvestment problem. Market integration should thus improve their incentive to invest in generation facilities. As argued by the proponents of market integration, it should allow more projects to be financed.

\section{Transportation Cost Reducing Investment}

In this section, we study the case in which the collective transportation cost can be reduced from $\gamma$ to $s \gamma$ with $s \in(0,1)$ by an investment of $I_{\gamma}>0$. We first consider the level of investment induced by the global welfare maximizer. Let $q_{i}^{* I_{\gamma}}$ be the quantity produced by firm $i=1,2$ in the case of investment. The optimal quantities are obtained by substituting $s \gamma$ into equation (11). The gross

26. Indeed, we find that $\hat{\Delta}_{a}<\hat{\Delta}_{b}<0$, and in the closed economy, investment is higher than the optimal value for the integrated market (i.e., it is inefficiently high) as soon as $\Delta<\hat{\Delta}_{b}$.

27. There is an over-investment problem in the open market if $\Delta \leq \hat{\Delta}_{c}$ and in the closed economy if $\Delta \leq \hat{\Delta}_{b}$.

28. We have tested many values for the parameters by simulations. The intervals $\hat{\Delta}_{a}, \hat{\Delta}_{b}$ always fell in $[-\hat{\Delta}, 0]$. For instance, for $d=2, \Lambda=0.15, \theta_{1}=1 / 2, \delta=9 / 10$, and $s=9 / 10$, we have that $-\hat{\Delta}=-0.5$, $\hat{\Delta}_{a}=-0.23, \hat{\Delta}_{b}=-0.08$ and $\hat{\Delta}_{c}=0.02$. Finally, the admissible values for $\Delta$ under Assumption A1 are in the interval $[-1.0,0.57]$ 
utilitarian welfare in the case of investment is the welfare function defined by equation (10) evaluated at the actualized quantities: $W^{* I_{\gamma}}=W\left(q_{1}^{* I_{\gamma}}, q_{2}^{* I_{\gamma}}\right)$. The global welfare maximizer chooses to invest if and only if $W^{* I_{\gamma}}-W^{*} \geq(1+\lambda) I_{\gamma}$. Let $I_{\gamma}^{*}$ be the maximal level of investment that satisfies this inequality:

$$
I_{\gamma}^{*}=\frac{1}{1+\lambda}\left[W^{* I_{\gamma}}-W^{*}\right]
$$

The non-cooperative equilibrium investment level of market integration is obtained using a similar method. The quantity produced by firm $i$ after investment $q_{i}^{\mathrm{OI}}$ is obtained by substituting $s \gamma$ into equation $(12)$. Let $W_{i}^{\mathrm{OI}}$ be the welfare function (6) of country $i=1,2$ evaluated at $\left(q_{1}^{\mathrm{OI}_{\gamma}}, q_{2}^{\mathrm{OI}{ }_{\gamma}}\right)$. The maximum level of investment that country $i$ is willing to make in the common market is

$$
I_{\gamma i}^{\mathrm{O}}=\max \left[0, \frac{1}{1+\lambda}\left[W_{i}^{O I_{\gamma}}-W_{i}^{\mathrm{O}}\right]\right]
$$

Intuitively, reducing transportation costs increases the business stealing effect. Although this increase in business stealing has an adverse effect on both countries, the negative impact is larger for the high cost firm. One can therefore check equation (12) to see that the market share of the less efficient country decreases after the investment. For this reason, the welfare effect generated by the transportation cost reducing investment in the less efficient country may be negative, so $I_{\gamma i}^{\mathrm{O}}$ can be equal to zero. In particular, this occurs for large values of $\Lambda$ (see Appendix E for details). In contrast, the investment always increases the gross welfare of the most efficient country. The maximal level of investment for the more efficient firm is always positive and higher than the maximal level of investment for the less efficient firm. Because the $\gamma$-reducing investment is a public good, in the common market, the level of investment that each country is willing to finance depends on the investment choice by the other country. The next lemma focuses on equilibria in pure strategy. ${ }^{29}$

\section{Lemma 1}

Let $\bar{I}_{\gamma}^{O}$ be the maximal level of investment for the more efficient firm and $\underline{I}_{\gamma}^{\mathrm{O}}$ be the maximal level of investment for the less efficient firm, as defined in (17).

- If $I_{\gamma}>\bar{I}_{\gamma}^{O}$, there is no investment.

- If $\underline{I}_{\gamma}^{\mathrm{O}}<I_{\gamma}, \leq \bar{I}_{\gamma}^{\mathrm{O}}$, the more efficient firm is the only one to invest.

29. There is also a mixed strategy equilibrium in which firm $i, i \neq j$ invests with probability $\pi_{i}=\left(W_{j}^{O I_{\gamma}}-(1+\lambda) I_{\gamma}-W_{j}^{O}\right) /\left(W_{j}^{O I_{\gamma}}-W_{j}^{O}\right)$. This equilibrium is inefficient because, with positive probability, either both firms invest or, alternatively, neither invests. Moreover, this equilibrium is not very realistic. An investment in transportation infrastructure requires a good deal of coordination between the two regions and is observed by all. 
- If $I_{\gamma} \leq \underline{I}_{\gamma}^{O}$, there are two Nash equilibria in pure strategy in which one of the firm invests and the other does not.

See Appendix E for proof.

Because of the public good nature of the investment, only one of the two firms invests, whereas the other free rides on the investment. The decision of the most efficient firm generally determines the maximal level of investment attainable in the common market. ${ }^{30}$ We are now ready to compare the equilibrium level with the optimum.

\section{Proposition 5}

In the integrated market, the investment level in $\gamma$-reducing technology is always suboptimal:

$$
\bar{I}_{\gamma}^{O} \leq \bar{I}_{\gamma}^{O}+\underline{I}_{\gamma}^{O} \leq I_{\gamma}^{*} \quad \forall \Delta, \Lambda \geq 0
$$

See Appendix E for proof.

In our specification, a $\gamma$-reducing investment has a public good nature. This investment equally reduces the transportation costs in both investing and non-investing countries. It is thus intuitive that investment level $\bar{I}_{\gamma}^{O}$ is sub-optimal. The investing country does not take into account the impact of the investment on the foreign country. However, the underinvestment problem goes deeper than the standard free riding in public good problem. Even if each country is willing to contribute to the point at which the cost of investment outweighs the welfare gains generated by investment (i.e., without free riding on the investment made by the other country), the total investment level $\bar{I}_{\gamma}^{\mathrm{O}}+\underline{I}_{\gamma}^{\mathrm{O}}$ would still be sub-optimal. To analyze the origin of this inefficiency, it is useful to study the countries' incentives to invest in a closed economy.

Let $q_{i}^{C I_{\gamma}}$ be the quantity produced by firm $i$ in the case of an investment in a closed economy. $q_{i}^{C I_{\gamma}}$ is obtained by substituting $s \gamma$ into equation (8). Let $W_{i}^{C I_{\gamma}}$ be the welfare function of country $i=1,2(6)$, evaluated at $q_{i}^{C I_{\gamma}}$. The investment is optimal in country $i$ if and only if $W_{i}^{C I_{\gamma}}-W_{i}^{C} \geq(1+\lambda) I_{\gamma}$ so that

$$
I_{\gamma i}^{C}=\frac{1}{1+\lambda}\left[W_{i}^{C I_{\gamma}}-W_{i}^{C}\right]
$$

Comparing (19) with (17) yields the next proposition.

30. Lemma 1 implies that the most efficient firm is willing to sustain relatively high levels of investment, and both firms are able to sustain lower levels. Because of the public good nature of the investment, the identity of the investing firm in this case is not important (and, in practice, might be determined by local circumstances). Our model only predicts that one of the firms will always want to invest for the defined thresholds. For projects above the maximal threshold, there will be no investment. 
FIGURE 3. $\gamma$-Reducing Investment

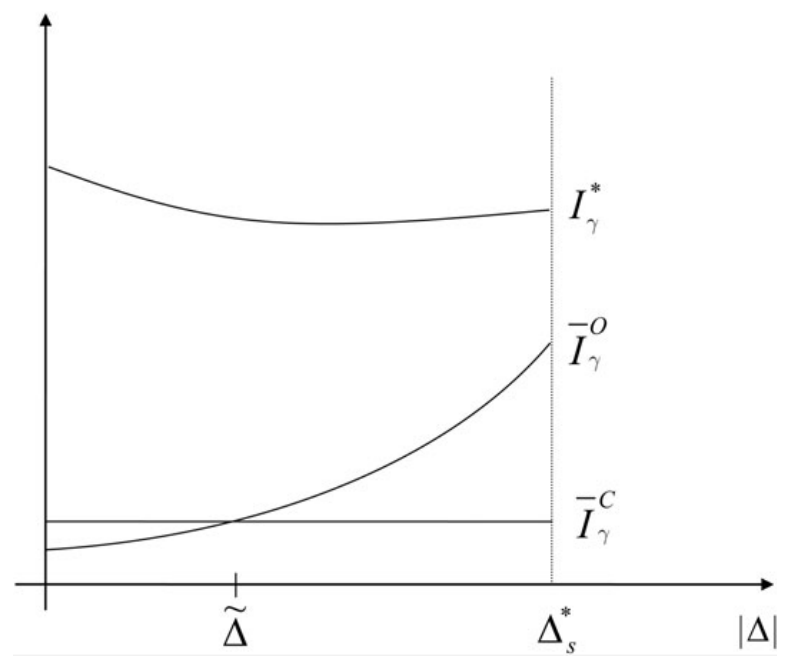

\section{Proposition 6}

Let $I_{\gamma}^{\mathrm{C}}$ be the maximal amount that the most efficient country is willing to invest to reduce transportation costs in the closed economy, and let $I_{\gamma}^{\mathrm{O}}$ be the maximal amount that it is willing to invest in the common market. There exists a $\tilde{\Delta}>0$ such that $I_{\gamma}^{\mathrm{O}}>I_{\gamma}^{\mathrm{C}}$ if and only if $|\Delta|>\tilde{\Delta}$.

See Appendix F for proof.

The maximal level of investment sustainable in the open economy is lower than it is in the case of autarky if $\Delta$ is relatively small. Investment reduces the costs of the competitor and makes the competitor more aggressive in the common market. The business stealing effect, while reducing the investing country's total welfare, also reduces its capacity to finance new investment. Market integration may thus generate an insufficient level of $\gamma$-reducing investment for two reasons. The first reason is that investment has a public good nature. The investing country does not internalize the benefits of foreign stakeholders. The second reason is that investment decreases the competitor's costs, worsening the business stealing effect. ${ }^{31}$ Figure 3 illustrates the results of Propositions 5 and 6.

Under market integration, when $\Delta$ is relatively small (i.e., $(|\Delta| \leq \tilde{\Delta})$, the maximal level of investment is not only sub-optimal but is also smaller than under a closed economy. When the two regions' costs are not drastically different, business stealing reduces the capacity to finance new investment, worsening the gap between the optimal investment and the equilibrium level. However,

31. In contrast, for $\Lambda=0, I_{\gamma}^{O}>I_{\gamma}^{C} \forall \Delta \geq 0$ and $I_{\gamma}^{O}-I_{\gamma}^{C}$ is an increasing function of $\Delta$. When public funds are free, business stealing is no longer a problem, so market integration always increases the level of sustainable investment compared to a closed economy. 
this poor outcome is unlikely to occur if the less efficient country can resist integration. Indeed, simulations suggest that $\tilde{\Delta}$ is higher than $\bar{\Delta}$, the threshold above which the most efficient country would win from market integration, but below $\hat{\Delta}$, the equivalent threshold for the less efficient country (see Figure 1). ${ }^{32}$

In contrast, when one country has a significant cost advantage (i.e., $|\Delta|>\tilde{\Delta}$ ), it is willing to invest more in the common market than under a closed economy because the investment increases its market share and profits. Integration can then help to increase investment, although not to the first best level. With a public good type of investment, there is always underinvestment. This result is in sharp contrast with the results from investment in generation, in which sectorial integration might lead to a level of investment that is inefficiently high. ${ }^{33}$

\section{Conclusion}

The integration of market economies is generally presented by its proponents as a powerful tool to stimulate investment in infrastructure industries. Intuitively, some investments that are oversized for a country should be profitable in an enlarged market. However, market integration in non-competitive industries has complex implications for welfare and investment.

When the cost difference between the two countries is large enough, market integration tends to increase the level of sustainable investment in generation. The investment level remains suboptimal because the countries endowed with cheap power (e.g., hydropower) do not fully internalize the surplus of the consumers in the foreign countries. These countries internalize only the sales. Symmetrically, when the investing country is less efficient than its competitor, it chooses an inefficiently high level of investment to close its productivity gap and win market share. With generation facilities, there is underinvestment in efficient technologies and over-investment in inefficient ones compared to the optimum. This result is in contrast with the systematic underinvestment problem that arises for interconnection and transportation facilities and with other public-good components of the industry. Free riding reduces incentives to invest, whereas business stealing reduces the capacity to finance new investment, especially in the importing country.

32. We have tested many values for the parameters by simulation, and the threshold $\tilde{\Delta}$ was always larger than $\hat{\Delta}$. For instance, for $d=2, \Lambda=0.15, \theta_{1}=1 / 2, \delta=9 / 10$ and $s=9 / 10$, we have $-\hat{\Delta}=-0.5$, $\bar{\Delta}=0.01$ and $\tilde{\Delta}=0.02$, whereas the admissible values under Assumption A1 are in the interval $[-1.0,0.57]$.

33. When the initial level of cost difference between the two regions is not large enough, the business stealing effect tilts the investment incentives in the wrong direction. For instance, if $\hat{\Delta}_{b}<\theta_{1}-\theta_{2}<\min \left\{\tilde{\Delta},-\hat{\Delta}_{b}\right\}$ with $\tilde{\Delta}$ defined as Proposition 6, then under market integration, country 2 underinvests in $\gamma$-reducing technology, whereas country 1 over-invests in $\theta$-reducing technology. The latter investment reduces the gap between the two regions' production costs, which further reduces the incentives of country 2 to invest in transportation and interconnection facilities. By virtue of Proposition 3, welfare decreases in both regions. 
These nuanced results are important for policy purposes. The countries involved in the creation of a power pool at an early stage should establish a supranational body to address the financing and management of interconnection links and other transmission infrastructures. A good example of a supra-national authority that has been created to address interconnection problems is the Electric Interconnection Project of Central America (SIEPAC). The six countries involved in the project (i.e., Guatemala, Nicaragua, El Salvador, Honduras, Panama, and Costa Rica) have established a common regulatory body, the Regional Commission of Electricity Interconnection (CRIE). The investment programs have been financed through loans obtained from several European banks together with the contributions of the member countries. The CRIE is now in charge of setting the access tariffs needed to repay the loans that financed the investment. Based on the CRIE experience, the West African power pool (WAPP) is also working on the creation of a regional regulatory body, "Organe de Régulation Régionale" (ORR). International organizations and aid agencies can play an important role in fostering the creation of these types of regional regulation authorities.

In addition to coordinating sustainable levels of investment in public good infrastructures, a central authority could help to move the non-cooperative equilibrium closer to the globally optimal solution. This objective is more ambitious and challenging than the former. Indeed, to mimic perfect integration, these agencies should be able to redistribute (i.e., share) the gains from trade and thus to transfer funds between countries. However, most countries have a policy of energy independence. Governments do not want to rely on their neighbors for their electricity supply and are thus very reluctant to abandon their national firm. Opening up this supranational regulatory authority to international involvement could have important policy implications in this context. An international authority would be able to limit hold-up problems and to enforce contracts. An international authority would also find it easier to tax energy trade to subsidize public good investment and possibly limit business stealing.

\section{APPENDIX}

\section{A. Proof of Proposition 1}

The supra-national regulator $i$ maximizes welfare (10) with respect to $q_{i}, i \in$ $\{1,2\}$. The first-order condition provides

$$
(1+\lambda)\left(d-q_{i}(1+\gamma)-q_{j}-\theta_{i}\right)+\frac{q_{i}+q_{j}}{2}=0 .
$$

First, consider the interior solution. Solving the system characterized in (20) for 
$i=1,2$ and allowing $\Lambda=\frac{\lambda}{1+\lambda}$, we obtain

$$
q_{i}^{*}=\frac{d-\frac{\theta_{1}+\theta_{2}}{2}}{1+\Lambda+\gamma}+\frac{\theta_{j}-\theta_{i}}{2 \gamma} .
$$

In this case, the total quantity $Q$ is provided by

$$
Q^{*}=q_{1}+q_{2}=2 \frac{d-\frac{\theta_{1}+\theta_{2}}{2}}{1+\Lambda+\gamma} .
$$

We now consider the shut-down case $q_{i}=0$. This case arises when $\theta_{i}-\theta_{j} \geq\left(2 \gamma\left(d-\theta_{j}\right)\right) /(1+2 \gamma+\Lambda)$. In this case, only the most efficient firm $j$ is allowed to produce, and the total quantity is provided by

$$
q_{j}^{*}=Q^{*}=2 \frac{\left(d-\theta_{j}\right)}{1+2 \gamma+\Lambda} .
$$

If $\theta_{i}<\theta_{\mathrm{j}}$, a symmetric condition describes the shut down case for firm $j, i \neq j$, i.e., $\quad \theta_{j}-\theta_{i} \geq\left(2 \gamma\left(d-\theta_{i}\right)\right) /(1+2 \gamma+\Lambda)$. Allowing $\theta_{\min }=\min \left\{\theta_{1}, \theta_{2}\right\} \quad$ and $|\Delta|=\left|\theta_{2}-\theta_{1}\right|=\left|\theta_{1}-\theta_{2}\right|$, Equation (11) resumes the results. Substituting into the inverse demand function (2), we then obtain the expression for the price.

\section{B. Proof of Proposition 2}

Maximizing the welfare function (6), we obtain the first-order condition:

$$
(1+\lambda)\left(d-\theta_{i}\right)-\frac{1}{4}\left[q_{j}(1+2 \lambda)+q_{i}(3+4 \lambda+4 \gamma(1+\lambda))\right]=0
$$

Rearranging terms and allowing $\Lambda=\lambda /(1+\lambda)$, we obtain the reaction function of regulator $i$ to the quantity induced by regulator $j(i \neq j)$, namely $q_{i}\left(q_{j}\right)$

$$
q_{i}\left(q_{j}\right)=\frac{4\left(d-\theta_{i}\right)-q_{j}(1+\Lambda)}{3+\Lambda+4 \cdot \gamma} .
$$

The equilibrium is given by the intersection of the two best response functions characterized in (21) (taking into account that quantities must be non-negative). If the intersection is reached when both quantities are positive, we have

$$
q_{i}^{\mathrm{O}}=4 \frac{d-\frac{\theta_{1}+\theta_{2}}{2}}{2(1+\gamma)+\Lambda}+\frac{\theta_{j}-\theta_{i}}{1+2 \gamma}
$$


FIGURE 4. Total Quantities $Q^{*}, Q^{O}$ and $Q^{C}$ as a function of $|\Delta|$

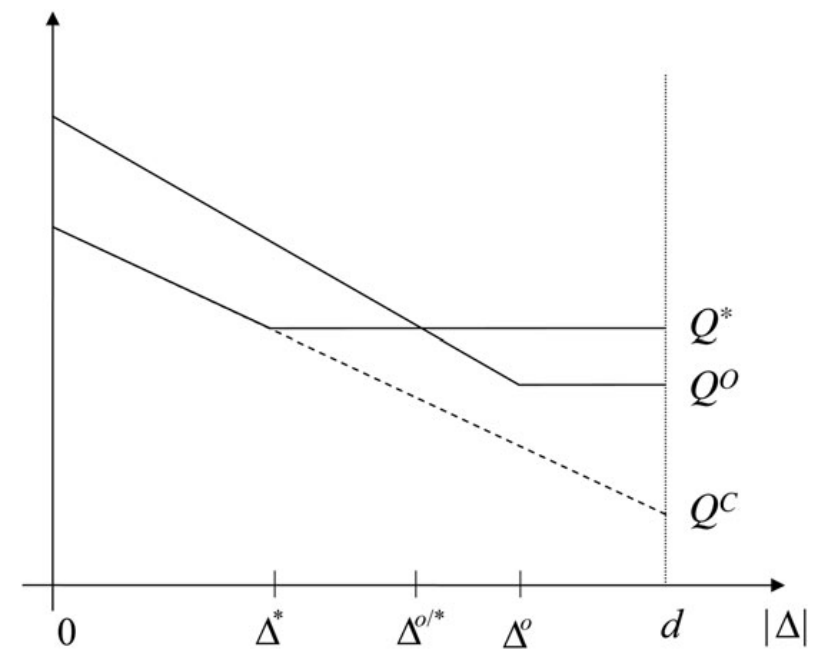

In this case, the total quantity $Q$ is provided by

$$
Q^{O}=q_{1}^{O}+q_{2}^{O}=4 \frac{d-\frac{\theta_{1}+\theta_{2}}{2}}{2(1+\gamma)+\Lambda} .
$$

However, we must also consider the shut-down case $q_{i}=0$. This situation arises when $q_{j} \geq 4\left(d-\theta_{i}\right) /(1+\Lambda)$ or, equivalently, $\theta_{i}-\theta_{j} \geq\left(2(1+2 \gamma)\left(d-\theta_{i}\right)\right) /(3+4 \gamma+\Lambda)$ $<0$. The shut-down case is thus written, for $\theta_{i}>\theta_{j}$,

$$
Q^{O}=q_{j}\left(q_{i}=0\right)=4 \frac{d-\theta_{j}}{3+4 \gamma+\Lambda} .
$$

If $\theta_{i}<\theta_{j}$, a symmetric condition describes the shut-down case for firm $j, i \neq j$. Letting $\theta_{\min }=\min \left\{\theta_{1}, \theta_{2}\right\}$ and $|\Delta|=\left|\theta_{2}-\theta_{1}\right|=\left|\theta_{1}-\theta_{2}\right|$, the expression for the optimal quantity is thus reassumed in (12). Substituting into the inverse demand function (2), we obtain the expression for the price given in (12).

Figure 4 illustrates the quantities result, representing, for a given $\theta_{\min }$, the quantity levels $Q^{*}, Q^{O}$ and $Q^{C}$ in the function of $|\Delta| \in[0, d]$. The flat sections correspond to the shut down of the less efficient producer.

Finally, comparing the shut-down threshold in the optimal case with the shutdown threshold of the less efficient firm in the integrated market with independent regulators yields $\Delta^{\mathrm{O}}>\Delta^{*}$. Figure 5 illustrates this result. The solid lines represent the equilibrium shut-down threshold of the less efficient firm in the 
FIGURE 5. Shut Down Threshold of the Less-Efficient Firm. Dotted line: optimal threshold; Solid line: non-cooperative equilibrium

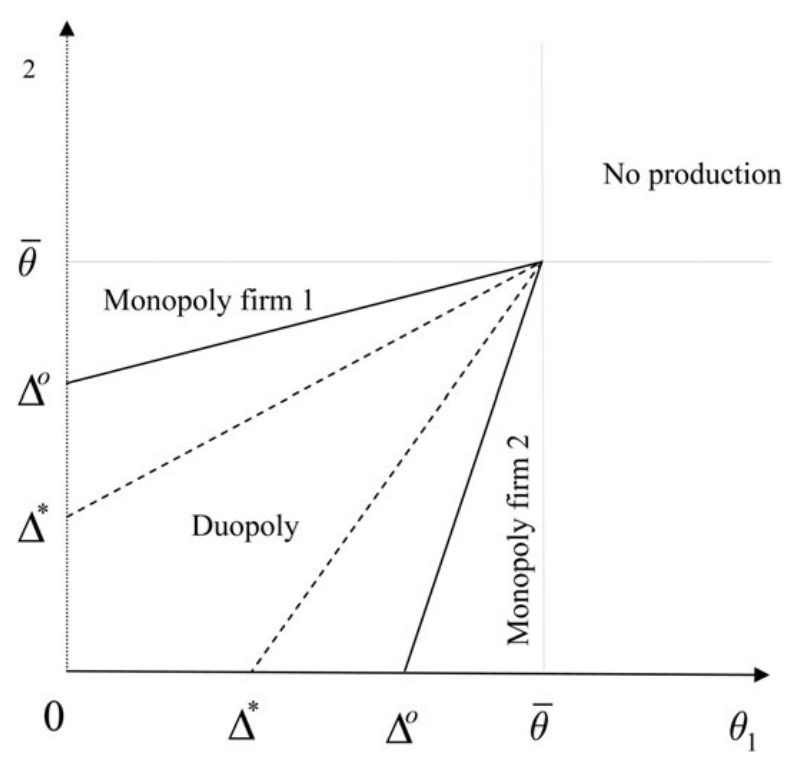

integrated market with independent regulators. The dotted lines represent the optimal threshold. The figure is plotted for $d=1, \Lambda=0.3, \gamma=0.5, \theta_{\mathrm{i}} \in[0,1]$ and $\theta_{\min }=0$. The same shape is obtained for any support, such as $\bar{\theta}-\underline{\theta} \geq\left(2 \gamma\left(d-\theta_{\min }\right)\right) /(1+2 \gamma+\Lambda)$.

\section{Proof of Proposition 3}

Consider country 1 (the same holds for country 2, inverting $\theta_{1}$ and $\theta_{2}$ and replacing $\Delta$ with $-\Delta$ in all expressions). Making a replacement for the participation constraint of the national firm, the welfare in country 1 in the case of closed economy is written as

$$
W_{1}^{C}=S\left(q_{1}^{C}\right)+\lambda P\left(q_{1}^{C}\right) q_{1}^{C}-(1+\lambda)\left(\theta_{1}+\gamma \frac{q_{1}^{C}}{2}\right) q_{1}^{C}
$$

and, in the case of an open economy,

$$
W_{1}^{O}=S\left(Q_{1}^{O}\right)-P\left(Q^{O}\right) Q_{1}^{O}+\lambda P\left(Q^{O}\right) q_{1}^{O}-(1+\lambda)\left(\theta_{1}+\gamma \frac{q_{1}^{O}}{2}\right) q_{1}^{O}
$$

Substituting for the value of the quantities (8) and (12) in (25) and (26), 
respectively, we compute the welfare gains from integration $W_{1}^{O}-W_{1}^{C}$.

$$
W_{1}^{O}-W_{1}^{C}=\Delta^{2} \Gamma_{1}(\gamma, \Lambda)+\Delta\left(d-\theta_{1}\right) \Gamma_{2}(\gamma, \Lambda)+\left(d-\theta_{1}\right)^{2} \Gamma_{3}(\gamma, \Lambda),
$$

where

$$
\Gamma_{1}(\gamma, \Lambda)=\left\{\begin{array}{lc}
\frac{2}{(3+4 \gamma+\Lambda)^{2}}, & \text { if } \Delta<-\frac{2(1+2 \gamma)\left(d-\theta_{2}\right)}{3+4 \gamma+\Lambda} \\
\frac{(1+\gamma(1-\Lambda))(3+4 \gamma+\Lambda)}{2(1+2 \gamma)^{2}(1-\Lambda)(2(1+\gamma)+\Lambda)^{2}}, & \text { if }-\frac{2(1+2 \gamma)\left(d-\theta_{2}\right)}{3+4 \gamma+\Lambda} \\
& \leq \Delta \leq \frac{2(1+2 \gamma)\left(d-\theta_{1}\right)}{3+4 \gamma+\Lambda} ; \\
0, & \text { if } \Delta>\frac{2(1+2 \gamma)\left(d-\theta_{1}\right)}{3+4 \gamma+\Lambda} .
\end{array}\right.
$$$$
\Gamma_{2}(\gamma, \Lambda)=\left\{\begin{array}{lr}
-\frac{8}{(3+4 \gamma+\Lambda)^{2}}, & \text { if } \Delta<-\frac{2(1+2 \gamma)\left(d-\theta_{2}\right)}{3+4 \gamma+\Lambda} \\
\frac{\Lambda(3+4 \gamma+\Lambda)}{(1+2 \gamma)(1+\Lambda)(2(1+\gamma)+\Lambda)^{2}}, & \text { if }-\frac{2(1+2 \gamma)\left(d-\theta_{2}\right)}{3+4 \gamma+\Lambda} \\
0, & \leq \Delta \leq \frac{2(1+2 \gamma)\left(d-\theta_{1}\right)}{3+4 \gamma+\Lambda} \\
0 & \text { if } \Delta>\frac{2(1+2 \gamma)\left(d-\theta_{1}\right)}{3+4 \gamma+\Lambda} .
\end{array}\right.
$$

$$
\Gamma_{3}(\gamma, \Lambda)=\left\{\begin{array}{cc}
\frac{15+16 \gamma^{2}+4 \gamma(5+3 \Lambda)+\Lambda(6+5 \Lambda)}{2(1-\Lambda)(1+\gamma+\Lambda)(3+4 \gamma+\Lambda)^{2}}, & \text { if } \Delta<-\frac{2(1+2 \gamma)\left(d-\theta_{2}\right)}{3+4 \gamma+\Lambda} ; \\
-\frac{\Lambda^{2}}{2(1-\Lambda)(1+\gamma+\Lambda)(2(1+\gamma)+\Lambda)^{2}}, & \text { if }-\frac{2(1+2 \gamma)\left(d-\theta_{2}\right)}{3+4 \gamma+\Lambda} \\
1+3 \Lambda & \leq \Delta \leq \frac{2(1+2 \gamma)\left(d-\theta_{1}\right)}{3+4 \gamma+\Lambda} ; \\
\frac{2(1+2 \gamma)\left(d-\theta_{1}\right)}{3+4 \gamma+\Lambda} .
\end{array}\right.
$$

$W_{1}^{O}-W_{1}^{C}$ is a U-shaped function of $\Delta$. For $\Lambda=0, W_{1}^{O}-W_{1}^{C}$ is always nonnegative, with the minimum $\Delta=0$, where $W_{1}^{O}-W_{1}^{C}$. For $\Lambda>0$, the minimum is attained in $\Delta=-\left(\Lambda(1+2 \gamma)\left(d-\theta_{1}\right)\right) /(1+\gamma(1+\Lambda))<0$. In this case, in $\Delta=0$, $W_{1}^{O}-W_{1}^{C}=-\Lambda^{2} /\left(2(1-\Lambda)(1+\gamma+\Lambda)(2(1+\gamma)+\Lambda)^{2}\right)<0$. The U shape and the condition $|\Delta| \leq d$ ensure the behavior described in Proposition 3 . 


\section{Proof of Proposition 4}

We begin computing the maximal level of investment for country 1 at the noncooperative equilibrium. The welfare in the absence of investment is defined in (26), and with investment, it is

$$
\begin{aligned}
W_{1}^{O I_{\theta}}= & S\left(Q_{1}^{\mathrm{OI}}\right)-P\left(Q^{O I_{\theta}}\right) Q_{1}^{\mathrm{OI} \theta}+\lambda P\left(Q^{O I_{\theta}}\right) q_{1}^{\mathrm{OI} \theta}-(1+\lambda)\left(\delta \theta_{1}+\gamma \frac{q_{1}^{\mathrm{OI}}}{2}\right) q_{1}^{\mathrm{OI}} \\
& -(1+\lambda) I_{\theta} .
\end{aligned}
$$

Replacing for the relevant quantities in Equation (15) and rearranging terms, we obtain

$$
\begin{gathered}
I_{\theta}^{*}=\frac{(1-\delta) \theta_{1}\left[d-\frac{(1+\delta) \theta_{1}}{2}+(1+\Lambda)\left(\frac{\Delta}{2 \gamma}+\frac{(1-\delta) \theta_{1}}{4 \gamma}\right)\right]}{1+\gamma+\Lambda} \\
I_{\theta}^{C}=\frac{(1-\delta) \theta_{1}\left[d-\frac{(1+\delta) \theta_{1}}{2}\right]}{1+\gamma+\Lambda} \\
I_{\theta}^{O}=\frac{(1-\delta) \theta_{1}\left[\left(d-\frac{(1+\delta) \theta_{1}}{2}\right)\left(4+8 \gamma^{2}+(3+\Lambda)(\Lambda+4 \gamma)\right)\right]}{(1+2 \gamma)(2(1+\gamma)+\Lambda)^{2}} \\
+\frac{(1-\delta) \theta_{1}\left[\left(\frac{\Delta}{1+2 \gamma}+\frac{(1-\delta) \theta_{1}}{2(1+2 \gamma)}\right)(1+\Lambda)(3+4 \gamma+\Lambda)\right]}{(1+2 \gamma)(2(1+\gamma)+\Lambda)^{2}}
\end{gathered}
$$

Then, $I_{\theta}^{*}>I_{\theta}^{\mathrm{C}}$ if and only if

$$
\Delta>\hat{\Delta}_{a}=-\frac{(1-\delta) \theta_{1}}{2}-\left[d-\frac{(1+\delta) \theta_{1}}{2}\right] \Gamma_{1}^{i}(\gamma, \Lambda),
$$

where

$$
\begin{aligned}
& \Gamma_{1}^{i}(\gamma, \Lambda)= \\
& \frac{2 \Lambda \gamma(1+2 \gamma)\left(3+4 \gamma^{2}+\Lambda(3+\Lambda+\gamma(7+3 \Lambda))\right.}{(1+\Lambda)\left(8 \gamma^{4}+(2+\lambda)^{2}+2 \gamma(3+\Lambda)^{2}+\gamma^{3}(26+6 \Lambda)+2 \gamma^{2}(16+\Lambda(7+\Lambda))\right)}
\end{aligned}
$$


$I_{\theta}^{*}>I_{\theta}^{\mathrm{O}}$ if and only if

$$
\Delta>\hat{\Delta}_{b}=-\frac{(1-\delta) \theta_{1}}{2}
$$

$I_{\theta}^{O}>I_{\theta}^{O}$ if and only if

$$
\Delta>\hat{\Delta}_{c}=-\frac{(1-\delta) \theta_{1}}{2}+\left[d-\frac{(1+\delta) \theta_{1}}{2}\right] \Gamma_{2}^{i}(\gamma, \Lambda)
$$

where

$$
\Gamma_{2}^{i}(\gamma, \Lambda)=\frac{\Lambda(1+2 \gamma)\left(3+4 \gamma^{2}+\Lambda(3+\Lambda+\gamma(7+3 \Lambda))\right)}{(1+\Lambda)(1+\gamma)(1+\gamma+\Lambda)(3+4 \gamma+\Lambda)}
$$

It is easy to see that if $\Lambda=0, \hat{\Delta}_{a}=\hat{\Delta}_{b}=\hat{\Delta}_{c}=-(1-\delta) \theta_{1} / 2<0$. Moreover, for all $\Lambda>0, \hat{\Delta}_{a}<\hat{\Delta}_{b}<\hat{\Delta}_{c}$. Finally, $\hat{\Delta}_{a}$ decreases in $\Lambda$, while $\hat{\Delta}_{c}$ increases. For a large enough $\Lambda, \hat{\Delta}_{c}$ is always positive.

\section{E. Proof of Lemma 1 and Proposition 5}

We begin computing the maximal level of investment for country 1 at the noncooperative equilibrium. We have

$$
\begin{aligned}
W_{1}^{O I_{\gamma}}= & S\left(Q_{1}^{O I_{\gamma}}\right)-P\left(Q^{O I_{\gamma}}\right) Q_{1}^{O I_{\gamma}}+\lambda P\left(Q^{O I_{\gamma}}\right) q_{1}^{O I_{\gamma}}-(1+\lambda)\left(\theta_{1}+s \gamma \frac{q_{1}^{O I_{\gamma}}}{2}\right) q_{1}^{O I_{\gamma}} \\
& -(1+\lambda) I_{\gamma} .
\end{aligned}
$$

Substituting the relevant quantities into this welfare function and into (26) and replacing them into Equation (17), we obtain

$$
I_{\gamma 1}^{O}=\Delta^{2} \Gamma_{1}^{i i}(\gamma, \Lambda)+\left(d-\theta_{1}\right) \Delta \Gamma_{2}^{i i}(\gamma, \Lambda)+\left(d-\theta_{1}\right)^{2} \Gamma_{3}^{i i}(\gamma, \Lambda),
$$

where

$$
\begin{aligned}
\Gamma_{1}^{i i}(\gamma, \Lambda) & =\frac{(1+s \gamma(1-\Lambda))(3+4 s \gamma+\Lambda)}{(1+2 s \gamma)^{2}(2(1+s \gamma)+\Lambda)^{2}}-\frac{(1+\gamma(1-\Lambda))(3+4 \gamma+\Lambda)}{(1+2 \gamma)^{2}(2(1+\gamma)+\Lambda)^{2}} \\
\Gamma_{2}^{i i}(\gamma, \Lambda) & =\frac{\Lambda(3+4 s \gamma+\Lambda)}{(1+2 s \gamma)(2(1+s \gamma)+\Lambda)^{2}}-\frac{\Lambda(3+4 \gamma+\Lambda)}{(1+2 \gamma)(2(1+\gamma)+\Lambda)^{2}} \\
\Gamma_{3}^{i i}(\gamma, \Lambda) & =\frac{2(1-s) \gamma(4(1+\gamma)(1+s \gamma)-\Lambda)^{2}}{(1+2 s \gamma)^{2}(2(1+s \gamma)+\Lambda)^{2}}
\end{aligned}
$$


$\Gamma_{1}^{i i}(\gamma, \Lambda)$ and $\Gamma_{2}^{i i}(\gamma, \Lambda)$ are positive $\forall s \in(0,1), \Lambda \in[0,1)$. $I_{\gamma i}^{O}$ is an upwardsloping parabola with its axis of symmetry in $\Delta=-\left(d-\theta_{i}\right) \Gamma_{2}^{i i}(\gamma, \Lambda) / 2 \Gamma_{1}^{i i}(\gamma, \Lambda)<0$, implying the following result:

\section{Result 1}

$I_{\gamma 1}^{\mathrm{O}}>I_{\gamma 2}^{\mathrm{O}}$ if and only if $\theta_{1}<\theta_{2}$.

By definition, this implies that $\bar{I}_{\gamma}^{\mathrm{O}}>\underline{I}_{\gamma}^{\mathrm{O}}$. This result is useful to prove Lemma 1.

\section{Proof of Lemma 1}

Because investment reduces the costs of both firms, if one firm invests, the best response of the other is to not invest. However, if one firm does not invest, the best response of the other firm is to invest whenever $I_{\gamma}<I_{\gamma}^{\mathrm{O}}$. From Result 1 , we know that $\bar{I}_{\gamma}^{O}>\underline{I}_{\gamma}^{O}$. Then, for $\underline{I}_{\gamma}^{O}<I_{\gamma}<\bar{I}_{\gamma}^{O}$, the less efficient firm never invests, and the more efficient firm does. For $I_{\gamma}<\underline{I}_{\gamma}^{O}$, a firm invests if and only if the other firm does not.

Before comparing the maximum level of investment $\bar{I}_{\gamma}^{O}$ with the optimal level $I_{\gamma}^{*}$ and the closed economy $\bar{I}_{\gamma}^{*}$, we prove that a $\gamma$-investment can reduce the welfare of the less efficient country. We have $\partial I_{\gamma 1}^{O} / \partial \Delta=2 \Delta \Gamma_{1}^{i i}(\gamma, \Lambda)+\left(d-\theta_{1}\right) \Gamma_{2}^{i i}(\gamma, \Lambda)$. Then, $\bar{I}_{\gamma}^{O}$ is strictly positive and increasing in $|\Delta|$, while $\underline{I}_{\gamma}^{O}$ is U shaped. The sign of $\underline{I}_{\gamma}^{O}$ is thus ambiguous. Let $W_{1}^{I_{\gamma}}-W_{1}$ be the impact of $\gamma$-reducing investment country 1 when $\Delta<0$ (i.e., $\theta_{2}<\theta_{1}$ ). By the definition of $\underline{I}_{\gamma}^{\mathrm{O}}$, we can write

$$
W_{1}^{I_{\gamma}}-W_{1}=\frac{\underline{I}_{\gamma}^{O}}{1-\Lambda}
$$

Then, the welfare gains of country 1 are positive if and only if $\underline{I}_{\gamma}^{\mathrm{O}}$ is positive. If $\underline{I}_{\gamma}^{\mathrm{O}}, \underline{I}_{\gamma}^{\mathrm{O}}$ is positive and decreasing in $|\Delta|$. We must prove that $\underline{I}_{\gamma}^{\mathrm{O}}$ might be negative for some $\Delta<0$. In $\Delta=-\left(2(1+2 s \gamma)\left(d-\theta_{2}\right)\right) /(1+\Lambda)$ (the minimal admissible value under A1), $W_{1}^{I_{\gamma}}-W_{1}$ is negative if and only if

$\Lambda>\bar{\Lambda}=\frac{\sqrt{9+8 s \gamma+4 \gamma(10+7 s \gamma+\gamma(3+\gamma(1+s))(5+\gamma(1+s)))}-(1+2 \gamma(2+\gamma(1+s)))}{1+2 \gamma}$

Then, $\Lambda>\bar{\Lambda}$ is a sufficient (although non-necessary) condition to achieve gains in the less efficient country that are smaller than zero for some $\Delta<0$.

Proof of Proposition 5

Let $Q^{*}=q_{1}^{*}+q_{2}^{*}$ and $Q^{* I_{\gamma}}=q_{1}^{* I_{\gamma}}+q_{2}^{* I_{\gamma}}$. The maximal investment at the global optimum is defined by (16). Global welfare in the case of non-investment 
and investment are, respectively,

$$
\begin{aligned}
W^{*}=S\left(Q^{*}\right)+ & \lambda P\left(Q^{*}\right) Q^{*}-(1+\lambda)\left(\theta_{1}+\gamma \frac{q_{1}^{*}}{2}\right) q_{1}^{*}-(1+\lambda)\left(\theta_{2}+\gamma \frac{q_{2}^{*}}{2}\right) q_{2}^{*} \\
W^{* I_{\gamma}}= & S\left(Q^{* I_{\gamma}}\right)+\lambda P\left(Q^{* I_{\gamma}}\right) Q^{* I_{\gamma}}-(1+\lambda) I_{\gamma} \\
& -(1+\lambda)\left[\left(\theta_{1}+s \gamma \frac{q_{1}^{* I_{\gamma}}}{2}\right) q_{1}^{* I_{\gamma}}+\left(\theta_{2}+s \gamma \frac{q_{2}^{* I_{\gamma}}}{2}\right) q_{2}^{* I_{\gamma}}\right]
\end{aligned}
$$

Replacing for the relevant quantities and rearranging terms, we obtain

$$
I_{\gamma}^{*}=\Delta^{2} \Gamma_{1}^{i i i}(\gamma, \Lambda)+\left(d-\theta_{\min }\right)|\Delta| \Gamma_{2}^{i i i}(\gamma, \Lambda)+\left(d-\theta_{\min }\right)^{2} \Gamma_{3}^{i i i}(\gamma, \Lambda),
$$

where

$$
\begin{aligned}
\Gamma_{1}^{i i i}(\gamma, \Lambda) & =\frac{1-s}{4 \gamma}\left[\frac{1}{s}+\frac{\gamma^{2}}{(1+s \gamma+\Lambda)(1+\gamma+\Lambda)}\right] \\
\Gamma_{2}^{i i i}(\gamma, \Lambda) & =-\frac{(1-s) \gamma}{(1+\gamma+\Lambda)(1+s \gamma+\Lambda)} \\
\Gamma_{3}^{i i i}(\gamma, \Lambda) & =\frac{(1-s) \gamma}{(1+\gamma+\Lambda)(1+s \gamma+\Lambda)}
\end{aligned}
$$

$I_{\gamma}^{*}$ is symmetric with respect to the origin $(\Delta=0)$ because at the global optimum, production is always reallocated in favor of the most efficient firm. Moreover, for both $\Delta>0$ and $\Delta<0$, production is U-shaped in $\Delta\left(\Gamma_{1}^{i i i}(\gamma, \Lambda)>0\right.$, $\forall s \in(0,1), \Lambda \in[0,1), \gamma \geq 0)$.

We now compare the thresholds $I_{\gamma}^{*}$ and $I_{\gamma}^{\mathrm{O}}$.

$$
\begin{aligned}
& I_{\gamma}^{*}-I_{\gamma}^{O}=\Delta^{2} \Gamma_{1}^{i v}(\gamma, \Lambda)+\left(d-\theta_{i}\right) \Delta \Gamma_{2}^{i v}(\gamma, \Lambda)-\left(d-\theta_{i}\right)^{2} \Gamma_{3}^{i v}(\gamma, \Lambda) \\
& \Gamma_{1}^{i v}(\gamma, \Lambda)=\frac{1}{s \gamma}+\frac{1}{1+s \gamma+\Lambda}-\frac{2(1+s \gamma(1-\Lambda))(3+4 s \gamma+\Lambda)}{(2(1+s \gamma))(2(1+s \gamma)+\Lambda)^{2}} \\
& -\frac{1}{\gamma}-\frac{1}{1+\gamma+\Lambda}+\frac{2(1+\gamma(1-\Lambda))(3+4 \gamma+\Lambda)}{(2(1+\gamma))(2(1+\gamma)+\Lambda)^{2}} \\
& \Gamma_{2}^{i v}(\gamma, \Lambda)=-\frac{1}{1+2 s \gamma}-\frac{1}{1+s \gamma+\Lambda}+\frac{4(1+s \gamma)^{2}+\Lambda}{(1+2 s \gamma)\left((2(1+s \gamma)+\Lambda)^{2}\right)} \\
& +\frac{1}{1+2 \gamma}+\frac{1}{1+\gamma+\Lambda}-\frac{4(1+\gamma)^{2}+\Lambda}{(1+2 \gamma)\left((2(1+\gamma)+\Lambda)^{2}\right)} \\
& \Gamma_{3}^{i v}(\gamma, \Lambda)=\frac{1}{1+s \gamma+\Lambda}-\frac{2(1+s \gamma)}{(2(1+s \gamma)+\Lambda)^{2}}-\frac{1}{1+\gamma+\Lambda}+\frac{2(1+\gamma)}{(2(1+\gamma)+\Lambda)^{2}}
\end{aligned}
$$


$\Gamma_{1}^{i \nu}(\gamma, \Lambda)$ is positive for all $s \in(0,1), \Lambda \in[0,1), \gamma>0$. Then, $I_{\gamma}^{*}-I_{\gamma}^{O}$ is a $\mathrm{U}$-shaped function of $\Delta$. Moreover, one can easily show that $I_{\gamma}^{*}-I_{\gamma}^{O}$ decreases with $\Lambda$. An increase in $\Lambda$ shifts the U curve downwards. Therefore, a sufficient condition for $I_{\gamma}^{*}-I_{\gamma}^{O}$ to always be positive is to have a positive minimum when $\Lambda=1$. Because $I_{\gamma}^{*}-I_{\gamma}^{\mathrm{O}}$ is a convex function of $\Delta$, the minimum is obtained from the first-order condition $\partial\left(I_{\gamma}^{*}-I_{\gamma}^{O}\right) / \partial \Delta=0$. In $\Lambda=1$, this minimum is equal to

$$
\begin{aligned}
& {\left[( 1 - s ) ^ { 2 } \left(57+292(1+s) \gamma+252(1+s(3+2 s)) \gamma^{2}+48(1+s)(7+s(12+7 s)) \gamma^{3}\right.\right.} \\
& +16(5+s(33+s(43+s(33+5 s)))) \gamma^{4}+28 s(1+s)(1+s(1+s)) \gamma^{5} \\
& \left.\left.+64 s^{2}\left(1+s^{2}\right) \gamma^{6}\right)\right] /\left[s(2+\gamma)(2+s \gamma)(1+2 s \gamma)^{2}(3+2 s \gamma)^{2}(3+4 \gamma(2+\gamma))\right] \\
& \quad>0 \forall s \in(0,1)
\end{aligned}
$$

Then, $I_{\gamma}^{*}-I_{\gamma}^{\mathrm{O}}$ is always positive.

We now show that $I_{\gamma}^{*}-\bar{I}_{\gamma}^{O}-\underline{I}_{\gamma}^{\mathrm{O}}$ is also positive. If $\underline{I}_{\gamma}^{\mathrm{O}}=0$, then $\bar{I}_{\gamma}^{\mathrm{O}}+\underline{I}_{\gamma}^{\mathrm{O}}=\bar{I}_{\gamma}^{\mathrm{O}}$ and the result has been proved above. If $\underline{I}_{\gamma}^{\mathrm{O}}>0$, we have

$$
\bar{I}_{\gamma}^{O}+\underline{I}_{\gamma}^{O}=\Delta^{2} \Gamma_{1}^{\nu}(\gamma, \Lambda)+\left(d-\theta_{i}\right) \Delta \Gamma_{2}^{\nu}(\gamma, \Lambda)+\left(d-\theta_{i}\right)^{2} \Gamma_{3}^{\nu}(\gamma, \Lambda),
$$

where

$$
\begin{aligned}
\Gamma_{1}^{\nu}(\gamma, \Lambda) & =\frac{(1-s) \gamma(3+4(\gamma+s \gamma(1+\gamma))}{(1+2 \gamma)^{2}(1+2 s \gamma)^{2}}-\frac{1+\gamma}{(2(1+\gamma)+\Lambda)^{2}}+\frac{1+s \gamma}{(2(1+s \gamma)+\Lambda)^{2}} \\
\Gamma_{2}^{\nu}(\gamma, \Lambda) & =-\frac{4(1-s) \gamma\left(4(1+\gamma)(1+s \gamma)-\Lambda^{2}\right)}{(2(1+\gamma)+\Lambda)^{2}(2(1+s \gamma)+\Lambda)^{2}} \\
\Gamma_{3}^{\nu}(\gamma, \Lambda) & =\frac{4(1-s) \gamma\left(4(1+\gamma)(1+s \gamma)-\Lambda^{2}\right)}{(2(1+\gamma)+\Lambda)^{2}(2(1+s \gamma)+\Lambda)^{2}} .
\end{aligned}
$$

Then,

$$
I_{\gamma}^{*}-\bar{I}_{\gamma}^{O}-\underline{I}_{\gamma}^{O}=\Delta^{2} \Gamma_{1}^{\nu i}(\gamma, \Lambda)+\left(d-\theta_{i}\right) \Delta \Gamma_{2}^{\nu i}(\gamma, \Lambda)-\left(d-\theta_{i}\right)^{2} \Gamma_{3}^{\nu i}(\gamma, \Lambda),
$$


where

$$
\begin{aligned}
\Gamma_{1}^{v i}(\gamma, \Lambda)= & \frac{1+\gamma}{(2(1+\gamma)+\Lambda)^{2}}-\frac{1+s \gamma}{(2(1+s \gamma)+\Lambda)^{2}}-\frac{1}{4(1+\gamma+\Lambda)}+\frac{1}{4(1+s \gamma+\Lambda)} \\
& -\frac{1}{4 \gamma(1+2 \gamma)^{2}}+\frac{1}{4 s \gamma(1+2 s \gamma)^{2}} \\
\Gamma_{2}^{v i}(\gamma, \Lambda)= & \frac{1}{(1+\gamma+\Lambda)}-\frac{1}{(1+s \gamma+\Lambda)}+\frac{4(1+\gamma)}{(2(1+\gamma)+\Lambda)^{2}}-\frac{4(1+s \gamma)}{(2(1+s \gamma)+\Lambda)^{2}} \\
\Gamma_{3}^{v i}(\gamma, \Lambda)= & \frac{(1-s) \gamma \Lambda^{2} 4(1+s(1+s)) \gamma^{2}+4(1+s) \gamma(3+2 \Lambda)+(2+\Lambda)(6+5 \Lambda)}{(1+\gamma+\Lambda)(1+s \gamma+\Lambda)(2(1+\gamma)+\Lambda)^{2}(2(1+s \gamma)+\Lambda)^{2}}
\end{aligned}
$$

$\Gamma_{1}^{v i}(\gamma, \Lambda)$ is positive for $s \in(0,1), \Lambda \in[0,1), \gamma \geq 0$, then $I_{\gamma}^{*}-I_{\gamma}^{J}$ is a convex U-shaped function of $\Delta$. Moreover, one can verify that the difference $I_{\gamma}^{*}-I_{\gamma}^{J}$ is decreasing with $\Lambda$. Then the difference is minimal in $\Lambda=0$, where

$$
I_{\gamma}^{*}-\bar{I}_{\gamma}^{O}-\underline{I}_{\gamma}^{O}=\frac{\gamma(1+2 \gamma)^{2}-s \gamma(1+2 s \gamma)^{2}}{4 \gamma(1+2 \gamma)^{2}(1+2 s \gamma)^{2}}>0, \forall s \in(0,1)
$$

Then, $I_{\gamma}^{*}-\bar{I}_{\gamma}^{O}-\underline{I}_{\gamma}^{O}$ is always positive.

\section{F. Proof of Proposition 6}

In the case of a closed economy, welfare with no investment is given by (25). If $I_{\gamma}$ is invested, the welfare function becomes

$$
W_{i}^{C I_{\gamma}}=S\left(q_{i}^{C I_{\gamma}}\right)+\lambda P\left(q_{i}^{C I_{\gamma}}\right) q_{i}^{C I_{\gamma}}-(1+\lambda)\left(\theta_{i}+s \gamma \frac{q_{i}^{C}}{2}\right) q_{i}^{C I_{\gamma}}-(1+\lambda) I_{\gamma}
$$

Substituting the equilibrium quantities into this expression and using equation (19), the maximal amount that regulator $i$ is willing to invest in a closed economy is

$$
I_{\gamma i}^{C}=\frac{(1-s) \gamma\left(d-\theta_{i}\right)^{2}}{2(1+\gamma+\Lambda)(1+s \gamma+\Lambda)} .
$$

We first check that $I_{\gamma}^{\mathrm{C}}$ is smaller than $I_{\gamma}^{*}$. Because $I_{\gamma}^{*}$ is a convex function of $\Delta$, whereas $I_{\gamma}^{C}$ is constant, $I_{\gamma}^{O}-I \gamma^{C}$ is also convex in $\Delta$. The derivative of $I_{\gamma}^{O}-I \gamma^{C}$ is zero at $\Delta=\left(2 s \gamma^{2}\left(d-\theta_{i}\right)\right) /\left(2 s \gamma^{2}+(1+s) \gamma(1+\Lambda)+\left(1+\Lambda^{2}\right)\right)$, where it 
reaches the minimum value:

$$
\frac{(1+s) \gamma\left(d-\theta_{i}\right)^{2}(1+\Lambda)(1+\gamma(1+s)+\Lambda)}{2(1+\gamma+\Lambda)(1+s \gamma+\Lambda)\left(2 s \gamma+(1+s) \gamma(1+\Lambda)(1+\gamma)^{2}\right)}>0
$$

Then, $I_{\gamma}^{O}-I \gamma^{C}$ is always positive.

We now compare $I_{\gamma}^{O}$ and $I_{\gamma}^{C}$. Because $I_{\gamma}^{O}$ is increasing and convex and $I_{\gamma}^{C}$ is constant, $I_{\gamma}^{O}-I_{\gamma}^{C}$ is also increasing and convex in $\Delta$. In particular, if $\Lambda=0$,

$$
\begin{aligned}
I_{\gamma}^{O}-I_{\gamma}^{C} & =\frac{(1-s) \gamma(11+4 \gamma(3(2+\gamma)+s(3+4 \gamma)(2+\gamma(1+s))))}{8(1+\gamma)(1+s \gamma)(1+2 \gamma)^{2}(1+2 s \gamma)^{2}} \Delta^{2} \geq 0 \forall s \\
& \in(0,1)
\end{aligned}
$$

Then, for $\Lambda=0$, the minimum is attained in $\Delta=0$, and $I_{\gamma}^{\mathrm{O}}-I_{\gamma}^{\mathrm{C}}$ is increasing with $|\Delta|$. However, if $\Lambda>0$ and $\Delta=0$,

$$
\begin{aligned}
I_{\gamma}^{O}-I_{\gamma}^{C}= & -\frac{1}{2}(1-s) \gamma\left(d-\theta_{i}\right)^{2} \\
& \times\left[\frac{1}{(1+s \gamma+\Lambda)}-\frac{1}{(1+\gamma+\Lambda)}+\frac{4(1+s \gamma)}{(2(1+s \gamma)+\Lambda)}-\frac{4(1+\gamma)}{(2(1+\gamma)+\Lambda)}\right]
\end{aligned}
$$

This result is negative for all $s \in(0,1), \Lambda \in[0,1), \gamma \geq 0$. From the increasing shape of $I_{\gamma}^{\mathrm{O}}$, there exists a $\tilde{\Delta}>0$ such that for all $\Delta>\tilde{\Delta}, I_{\gamma}^{\mathrm{O}}>I_{\gamma}^{\mathrm{C}}$.

\section{G. Asymmetric Demand}

In the main text, we have assumed that countries only differ in their available technology. We now check the robustness of our results to the case in which demands are asymmetric. Let

$$
p_{i}=d_{i}-Q_{i}
$$

where $i$ denotes the country, $i=1,2$. To make meaningful comparisons, we keep the total size of the market constant in this extension compared to our base case, i.e.,

$$
d=\frac{d_{1}+d_{2}}{2}
$$

Moreover, to ensure interior solutions, we make the following assumption:
(A0bis) $\min \left\{d_{1}, d_{2}\right\}>\bar{\theta}$.

Under autarky, the results are the same as in the base case, with $d$ replaced by $d_{i}, i=1,2$. In the integrated market, total demand is as in equation (2): $p=d-Q / 2$ with $Q=q_{1}+q_{2}$. 


\section{Full Integration}

In the case of full integration, we first determine the optimal consumption sharing rule, maximizing $S_{1}\left(Q_{1}\right)+S_{2}\left(Q_{2}\right)$ under the constraint that $Q_{1}+Q_{2}=Q$. Because $S_{i}\left(Q_{i}\right)=d_{i} Q_{i}-Q_{i}^{2} / 2$, we deduce that $Q_{i}=\left(Q_{1}+Q_{2}\right) / 2+\left(d_{i}-d_{j}\right) / 2$. Computing the total consumer surplus $S_{1}\left(Q_{1}\right)+S_{2}\left(Q_{2}\right)$, we now obtain $S_{1}\left(Q_{1}\right)+S_{2}\left(Q_{2}\right)=\left(d_{1}-d_{2}\right)^{2} / 4+\left(d_{1}+d_{2}\right)\left(Q_{1}+Q_{2}\right) / 2-\left(Q_{1}+Q_{2}\right)^{2} / 4$.

Substituting this expression into the total welfare function (9), the maximization problem of the supranational regulator is the same as in the base case plus a constant term $\left(d_{1}-d_{2}\right)^{2} / 4$. Then, the optimal quantities are the same as in (11). Replacing these optimal quantities in the welfare functions (9) and replacing the autarky quantities from equation (8) evaluated at $d_{i}$ in the welfare function (6), we compute the welfare gains from integration $W_{a s y}^{*}-W_{a s y}^{C}$ and compare them with those obtained in the base case of symmetric demand.

$$
W_{a s y}^{*}-W_{a s y}^{C}=W^{*}-W^{C}+\frac{\left(d_{2}-d_{1}\right)\left(\left(d_{2}-d_{1}\right)\left(2 \gamma(1-\Lambda)-2 \Lambda^{2}+1\right)+2 \Delta\right)}{4(1-\Lambda)(\gamma+\Lambda+1)} \geq 0
$$

The additional term in the welfare gains can be positive or negative. The term is positive when $d_{2}-d_{1}$ is positive and $\Delta=\theta_{2}-\theta_{1}$ is relatively large and when $d_{2}-d_{1}$ is negative and $\Delta$ is relatively small. Demand asymmetry plays a similar role to cost asymmetry. To see this point, consider the limit case in which $\Delta=0$ (i.e., generation costs are identical). This case implies that $W^{*}-W^{C}=(1+\Lambda) \Delta^{2} /(4 \gamma(1-\Lambda)(1+\gamma+\Lambda))=0$ and that $W_{a s y}^{*}-W_{a s y}^{C}=\left(2 \gamma(1-\Lambda)-2 \Lambda^{2}+1\right)\left(d_{2}-d_{1}\right)^{2} /(4(1-\Lambda)(1+\gamma+\Lambda))$. Due to the quadratic shape of the transportation cost function, the smaller country has a lower marginal cost. THerefore, when the smaller country is also the most efficient one, integration allows the regulator to expand the smaller country's market share to exploit the low generation and transportation costs. Reallocating production toward the producer with the smaller national market increases productive efficiency and the total welfare gains from trade.

\section{Sectorial Integration with Asymmetric Regulation}

Consumer surplus is written $S_{i}\left(Q_{i}\right)=d_{i} Q_{i}-Q_{i}^{2} / 2$ and $Q_{i}=Q / 2+\left(d_{i}-d_{j}\right) / 2$, where $Q=Q_{1}+Q_{2}=q_{1}+q_{2}$ and $i, j=1,2 i \neq j$. Substituting this expression into (6) yields the national welfare function. The regulator of country i chooses $q_{i}$ to maximize this function given the quantity $q_{j}$ chosen by the regulator of country j. At the non-cooperative equilibrium, we have

$$
q_{i}^{O}=4 \frac{d-\frac{\theta_{1}+\theta_{2}}{2}}{2(1+\gamma)+\Lambda}+\frac{\theta_{j}-\theta_{i}}{1+2 \gamma}+\frac{(1-\Lambda)\left(d_{i}-d_{j}\right)}{2+4 \gamma}
$$


The last term, which cancels out when $d_{1}=d_{2}$, is an additional term due to the asymmetry of demand. Replacing these quantities in the social welfare function (6), we can compute the welfare gains. As in Appendix C, we focus without loss of generality on country 1 . The results for country 2 are symmetrical. The welfare gain of country $1, W_{1, a s y}^{O}-W_{1, a s y}^{C}$, is equal to the gain obtained in the symmetric case plus an additional term $\zeta\left(d_{2}-d_{1}, \Delta, \Lambda, \gamma, \theta_{1}\right)$ :

$$
W_{1, a s y}^{O}-W_{1, a s y}^{C}=W_{1}^{O}-W_{1}^{C}+\zeta\left(d_{2}-d_{1}, \Delta, \Lambda, \gamma, \theta_{1}\right)
$$

where

$$
\begin{aligned}
\zeta\left(d_{2}-d_{1}, \Delta, \Lambda, \gamma, \theta_{1}\right)= & \frac{1}{8}\left(\left(d_{2}-d_{1}\right) \Delta \phi_{1}(\gamma, \Lambda)+\left(d_{2}-d_{1}\right)^{2} \phi_{2}(\gamma, \Lambda)+\left(d_{2}-d_{1}\right)\right. \\
& \left.\times\left(d_{1}-\theta_{1}\right) \phi_{3}(\gamma, \Lambda)\right)
\end{aligned}
$$

and

$$
\begin{aligned}
\phi_{1}(\gamma, \Lambda)= & \frac{4 \gamma(3+4 \gamma+\Lambda)}{(1+2 \gamma)^{2}(2+2 \gamma+\Lambda)} \geq 0 \\
\phi_{2}(\gamma, \Lambda)= & \frac{8 \gamma^{4}(1-\Lambda)+2 \gamma^{3}((4-7 \Lambda) \Lambda+7)+\gamma^{2}(6+\Lambda(19+(2-7 \Lambda) \Lambda)+6)}{(1+2 \gamma)^{2}(1-\Lambda)(1+\gamma+\Lambda)(2+2 \gamma+\Lambda)} \\
& +\frac{\Lambda \gamma(3-\Lambda)(2+\Lambda(4+\Lambda))+\Lambda^{2}(2+\Lambda)}{(1+2 \gamma)^{2}(1-\Lambda)(1+\gamma+\Lambda)(2+2 \gamma+\Lambda)} \geq 0 \\
\phi_{3}(\gamma, \Lambda)= & \frac{4 \Lambda\left(4 \gamma^{2}+\gamma(3+5 \Lambda)+\Lambda(2+\Lambda)\right)}{(1+2 \gamma)(1-\Lambda)(1+\gamma+\Lambda)(2+2 \gamma+\Lambda)} \geq 0
\end{aligned}
$$

The additional effect $\zeta$ is decomposed into three terms. The first term, which is identical for both countries, has the sign of $\left(d_{2}-d_{1}\right) \Delta$ : it is positive whenever $\left(d_{2}-d_{1}\right)$ and $\Delta=\theta_{2}-\theta_{1}$ have the same sign. These variables have the same sign when country 1 is small and possesses the most efficient technology or when it is large and endowed with the less efficient technology. The second term is always positive and increases with the absolute value of $\left(d_{2}-d_{1}\right)$. This term is also identical for both countries. This term captures the efficiency gains related to production reallocation in the presence of a positive quadratic transportation cost.

Finally, because $\left(d_{i}-\theta_{\mathrm{i}}\right)$ is always positive by assumption $\mathrm{A} 0$, the third term has the sign of $\left(d_{j}-d_{i}\right)$ for country $i$, meaning that it is positive for the smallest country and negative for the largest one.

Because the first and second terms are identical for both countries whereas the third term is positive for the small country and negative for the large country, we deduce that, everything else being equal, the smaller country always wins more from integration than the larger one. 
FIGURE 6. The Welfare Gains $W_{1, a s y}^{O}-W_{1, a s y}^{C}, \Delta=0, \Lambda=1 / 3, \gamma=10$

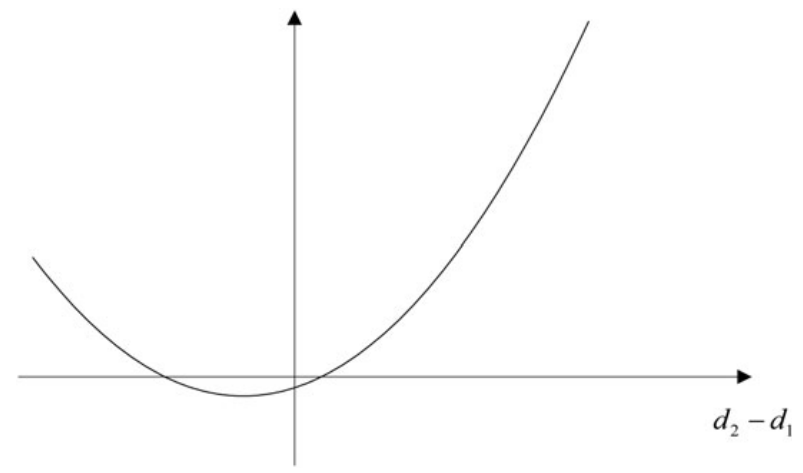

FIGURE 7. The Welfare Gains $W_{1, a s y}^{O}-W_{1, a s y}^{C}, \Delta=0, \Lambda=1 / 3, \gamma=1$

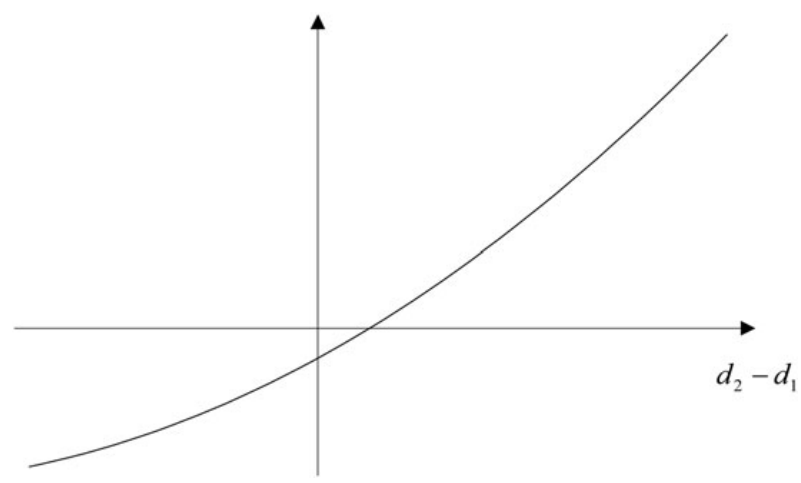

The net effect of $\zeta$ depends on the opportunity cost of public funds. When $\Lambda$ is relatively small, the first term in $\zeta$ is the largest. Compared to the base case, the welfare gains increase when the smallest country is also the most efficient. In contrast, the two effects (i.e., generation and transportation costs) contradict each other when the large country is the most efficient, so the welfare gains are lower than in the base case. Now, for large values of $\Lambda$, the third term in $\zeta$ tends to be the largest, unless $\gamma$ is also very large. Thus, for a sufficiently large $\Lambda$, the additional welfare gains obtained with asymmetric demand tend to be positive for the smaller country and negative for the larger one.

We next want to check that our result-that market integration is welfare degrading when countries are too similar and that fiscal issues are important-is 
robust to asymmetric demand. Let $\Delta=0$. The welfare gains are written as

$$
\begin{aligned}
W_{1, a s y}^{O}-W_{1, a s y}^{C}= & \Gamma_{1}(\Lambda, \gamma)\left(d-\theta_{1}\right)^{2}+\frac{1}{8}\left(\left(d_{2}-d_{1}\right)^{2} \phi_{2}(\gamma, \Lambda)+\left(d_{2}-d_{1}\right)\left(d_{1}\right.\right. \\
& \left.\left.-\theta_{1}\right) \phi_{3}(\gamma, \Lambda)\right)
\end{aligned}
$$

where $\Gamma_{1}(\Lambda, \gamma)=-\Lambda^{2} /\left((1-\Lambda)(1+\gamma+\Lambda)(2+2 \gamma+\Lambda)^{2}\right)<0$. For $d_{2}=d_{1}$, the term $\Gamma_{1}(\Lambda, \gamma)\left(d-\theta_{1}\right)^{2}$ corresponds to the welfare gains in the base model (see Appendix $\mathrm{C}$ when $\Delta=0$ ). If $\Lambda>0$, then the welfare gains are always negative for $d_{1}=d_{2}$ and $\Delta=0$. By continuity, this net welfare loss result holds true for strictly positive values of $\left|d_{2}-d_{1}\right|$, as illustrated in figures 6 and 7 . These figures show that both countries lose from integration if they are too similar (i.e., the engine of integration is cost complementarities).

The welfare gain is a convex function of $d_{2}-d_{1}$ when $\Delta=0$. The function is increasing for $d_{2}-d_{1} \geq 0$ (i.e., for the smaller country) and, depending on the value of $\gamma$, is U-shaped or decreasing for $d_{2}-d_{1} \leq 0$ (i.e., for the larger country). The U-shaped result is similar to the result illustrated in figure 1 because when $\gamma$ is large, $d_{2}-d_{1}$ plays the same role as $\Delta$. When transportation costs are very large, both countries gain from integration (one through export profits, the other through a reduction in the price).

\section{REFERENCES}

Armstrong, M., and D. Sappington. 2005. "Recent Developments in the Theory of Regulation." In Handbook of Industrial Organization, 1570-1687. Elsevier.

Attwood, E. 2009, August 6. "Iraq Admits Inability to Pay Electricity Bill.” http://www.utilities-me.com/ article-79-iraq_admits_inability_to_pay_electricity_bill/.

Auriol, E. 1998. "Deregulation and Quality." International Journal of Industrial Organization 16 (2):169-94.

Auriol, E., and P.M. Picard. 2006. "Infrastructure and Public Utilities Privatization in Developing Countries.” World Bank Policy Research Working Paper no. WPS 3950. World Bank, Washington, DC.

Biglaiser, G., and C.A. Ma. 1995. "Regulating a Dominant Firm, Unknown Demand and Industry Structure." RAND Journal of Economics 26: 1-19.

Brander, J. 1997. “Strategic Trade Theory.” In Handbook of Industrial Organization, 1395-1450. Elsevier.

Brander, J., and P. Krugman. 1983. “A Reciprocal Dumping Model of International Trade.” Journal of International Economics 15 (3): 313-21.

Brander, J.A., and B.J. Spencer. 1983. "International R \& D Rivalry and Industrial Strategy." The Review of Economic Studies 50 (4): 707-22.

Caillaud, B. 1990. "Regulation, Competition and Asymmetric Information.” Journal of Economic Theory 52: $87-100$.

Collie, D.R. 2000. "State Aid in the European Union: The Prohibition of Subsidies in an Integrated Market.” International Journal of Industrial Organization 18 (6): 867-84. 
Estache, A., and A. Iimi. 2008. "Procurement Efficiency for Infrastructure Development and Financial Needs Reassessed.” World Bank Policy Research Working Paper Series no. 4662. World Bank, Washington, DC.

Estache, A., and L. Wren-Lewis. 2009."Toward a Theory of Regulation for Developing Countries: Following Jean-Jacques Laffont's Lead.” Journal of Economic Literature 47 (3): 729-70.

Estache, A., S. Perelman, and L. Trujillo. 2005. "Infrastructure Performance and Reform in Developing and Transition Economies: Evidence From a Survey of Productivity Measures.” World Bank Policy Research Working Paper 3514. World Bank, Washington, DC.

Feenstra, R.C. 2008. Advanced International Trade: Theory and Evidence. Princeton, NJ: Princeton University Press.

Herald. 2011, December 22. “Zimbabwe: ZESA Owed U.S.D. 537 Million in Unpaid Bills.” http:// allafrica.com/stories/201112230164.html.

International Electricity Agency. 2006. World Energy Outlook. Paris, France: IEA.

Joskow, P.L., and R. Schmalensee. 1985. Markets for Power. Cambridge, MA: MIT Press.

Laffont, J.J. 2005. Regulation and Development. Cambridge, UK: Cambridge University Press.

Manibog, R., F. Dominguez, and S. Wegner. 2003. Power for Development- A Review of the World Bank Group's Experience with Private Participation in the Electricity Sector. Washington, DC: The International Bank for Reconstruction and Development, The World Bank.

Markusen, J.R. 1981. "Trade and the Gains from Trade with Imperfect Competition." Journal of International Economics 11 (4): 531-51.

Navalona, R. 2012, August 16. “Madagascar: Antsiranana - Délestage depuis dix mois.” http://fr. allafrica.com/stories/201208170568.html.

Neary, J.P. 2003. “Globalization and Market Structure.” Journal of the European Economic Association 1 (2-3): 245-71.

Rosnes, O., and H. Vennemo. 2008. "Powering Up: Costing Power Infrastructure Investment Needs in Southern and Eastern Africa.” AICD, Background Paper. World Bank, Washington, DC.

Snow, A., and R.S. Warren. 1996. "The Marginal Welfare Cost of Public Funds: Theory and Estimates." Journal of Public Economics 61 (2): 289-305.

Sparrow, F.T., W. Masters, and B.H. Bowen. 2002. "Electricity Trade and Capacity Expansion Options in West Africa.” Purdue University, West Lafayette, IN.

World Bank. 1998. World Development Indicators 1998. Washington, DC: World Bank. 